\title{
Large-Scale Chondroitin Sulfate Proteoglycan Digestion with Chondroitinase Gene Therapy Leads to Reduced Pathology and Modulates Macrophage Phenotype following Spinal Cord Contusion Injury
}

\author{
Katalin Bartus, ${ }^{1 \star}$ Nicholas D. James, ${ }^{1 *}$ Athanasios Didangelos, ${ }^{1}$ Karen D. Bosch, ${ }^{1}$ Joost Verhaagen, ${ }^{2}$ \\ Rafael J. Yáñez-Muñoz, ${ }^{3}$ John H. Rogers, ${ }^{4}$ Bernard L. Schneider, ${ }^{5}$ Elizabeth M. Muir, ${ }^{4}$ and Elizabeth J. Bradbury ${ }^{1}$ \\ ${ }^{1}$ King's College London, Regeneration Group, The Wolfson Centre for Age-Related Diseases, London SE1 1UL, United Kingdom, ${ }^{2}$ Laboratory for \\ Neuroregeneration, Netherlands Institute for Neuroscience, 1105BA Amsterdam, The Netherlands, ${ }^{3}$ School of Biological Sciences, Royal Holloway, \\ University of London, Egham, Surrey TW20 0EX, United Kingdom, ${ }^{4}$ Department of Physiology Development and Neuroscience, University of Cambridge, \\ Cambridge CB2 3EG, United Kingdom, and 5Brain Mind Institute, Ecole Polytechnique Fédérale de Lausanne, 1015 Lausanne, Switzerland
}

Chondroitin sulfate proteoglycans (CSPGs) inhibit repair following spinal cord injury. Here we use mammalian-compatible engineered chondroitinase $\mathrm{ABC}(\mathrm{Ch} A \mathrm{BC})$ delivered via lentiviral vector ( $\mathrm{LV}-\mathrm{Ch} A \mathrm{BC})$ to explore the consequences of large-scale CSPG digestion for spinal cord repair. We demonstrate significantly reduced secondary injury pathology in adult rats following spinal contusion injury and $\mathrm{LV}-\mathrm{ChABC}$ treatment, with reduced cavitation and enhanced preservation of spinal neurons and axons at 12 weeks postinjury, compared with control (LV-GFP)-treated animals. To understand these neuroprotective effects, we investigated early inflammatory changes following LV-ChABC treatment. Increased expression of the phagocytic macrophage marker CD68 at $3 \mathrm{~d}$ postinjury was followed by increased CD206 expression at 2 weeks, indicating that large-scale CSPG digestion can alter macrophage phenotype to favor alternatively activated M2 macrophages. Accordingly, ChABC treatment in vitro induced a significant increase in CD206 expression in unpolarized monocytes stimulated with conditioned medium from spinal-injured tissue explants. LV-ChABC also promoted the remodelling of specific CSPGs as well as enhanced vascularity, which was closely associated with CD206-positive macrophages. Neuroprotective effects of LV-ChABC corresponded with improved sensorimotor function, evident as early as 1 week postinjury, a time point when increased neuronal survival correlated with reduced apoptosis. Improved function was maintained into chronic injury stages, where improved axonal conduction and increased serotonergic innervation were also observed. Thus, we demonstrate that ChABC gene therapy can modulate secondary injury processes, with neuroprotective effects that lead to long-term improved functional outcome and reveal novel mechanistic evidence that modulation of macrophage phenotype may underlie these effects.

Key words: chondroitinase; contusion; gene therapy; neuroprotection; spinal cord injury

\section{Introduction}

A major obstacle preventing repair following spinal cord injury is the presence in the extracellular matrix (ECM) of inhibitory

Received Oct. 10, 2013; revised Feb. 25, 2014; accepted Feb. 25, 2014.

Author contributions: E.J.B. designed research; K.B., N.D.J., A.D., and K.D.B. performed research; J.V., R.J.Y.-M., J.H.R., B.L.S., and E.M.M. contributed unpublished reagents/analytic tools; K.B., N.D.J., and A.D. analyzed data; K.B., N.D.J., A.D., and E.J.B. wrote the paper.

This work was supported by the United Kingdom Medical Research Council (Senior Non-Clinical Fellowship Award G1002055), the International Spinal Research Trust (SRT101), the Henry Smith Charity, the Darwin Trust of Edinburgh, and the International Foundation for Research in Paraplegia (to E.J.B.); the International Spinal Research Trust (TR1002 to E.M.M.); and European Union FP7 projects Plasticise (Project Number 223524, to B.L.S.) and Persist (222878, to R.J.Y.-M.). We thank F. Pidoux and S.G. Ahmed for technical assistance in production of LV suspensions; E.R. Burnside, C. Kathe, and P. Hemachudha for assistance with histology; and S.B. McMahon, G. Cook, and R.J. Keynes for advice and comments on the manuscript.

*K.B. and N.D.J. contributed equally to this work.

The authors declare no competing financial interests.

Correspondence should be addressed to Elizabeth J. Bradbury, King's College London, Regeneration Group, The Wolfson Centre for Age-Related Diseases, Wolfson Wing, Hodgkin Building, Guy's Campus, London Bridge, London SE1 1UL, United Kingdom. E-mail: elizabeth.bradbury@kcl.ac.uk.

DOI:10.1523/JNEUROSCI.4369-13.2014

Copyright $\odot 2014$ the authors $\quad 0270-6474 / 14 / 334822-15 \$ 15.00 / 0$ chondroitin sulfate proteoglycans (CSPGs), which become more abundant after injury (Silver and Miller, 2004; Carulli et al., 2005; Bradbury and McMahon, 2006). Chondroitinase ABC (ChABC) is a bacterial enzyme that degrades CSPG glycosylated sugar chains, which are thought to confer much of the inhibitory properties of CSPGs. In vivo delivery of this enzyme has led to beneficial effects on repair following experimental spinal cord injury in models involving partial (Bradbury et al., 2002; Houle et al., 2006; Massey et al., 2006; Cafferty et al., 2008; García-Alías et al., 2009; Alilain et al., 2011; Jefferson et al., 2011) or complete (Lee et al., 2013) transection of the spinal cord. However, delivery methods to date have been suboptimal, largely due to issues of enzyme instability, which necessitates invasive and repeated administration to the spinal cord. This is largely thought to be the reason that $\mathrm{ChABC}$ has not proved as effective in treating more clinically relevant contusive-type injuries (involving nonpenetrating blunt trauma, compression, and bruising). The few studies that have applied $\mathrm{ChABC}$ to injuries that more closely mimic the progressive pathology of a human spinal cord injury have generated 
mixed results, with some beneficial effects on recovery of locomotor function reported with ChABC delivered by repeated intrathecal infusion (Caggiano et al., 2005; Tauchi et al., 2012) or as part of a combination therapy (Tom et al., 2009a; KarimiAbdolrezaee et al., 2010), while other studies have failed to show efficacy following single intraspinal ChABC injections (Iseda et al., 2008; Tom et al., 2009b; Jakeman et al., 2011).

A gene therapy approach, whereby host cells are transduced with a ChABC viral vector, is emerging as a promising tool for achieving stable delivery of the ChABC enzyme. A number of gene delivery methods have been tried, including transcriptionally targeted glial expression of ChABC in transgenic mice (Cafferty et al., 2007) or Tet-inducible adenoviral vectors (Curinga et al., 2007) or lentiviral vectors (LVs) (Jin et al., 2011) that encode engineered chondroitinase AC. However, the degree of CSPG digestion achieved with these methods has been relatively modest, largely because the eukaryotic $N$-glycosylation system disrupts folding and secretion of bacterial proteins, resulting in poor enzyme release by mammalian cells or inactivity of the enzyme. The recent genetic mutation of bacterial ChABC cDNA by sitedirected mutagenesis of key $\mathrm{N}$-glycosylation sites allows the expression and efficient secretion of active ChABC enzyme by mammalian cells (Muir et al., 2010) and LVs incorporating this mammalian-compatible ChABC gene (LV-ChABCs) have been produced, with evidence of active $\mathrm{ChABC}$ expression and transport following in vivo brain injections and some axonal sprouting observed in the spinal cord 4 weeks after dorsal column crush injury and LV-ChABC injection (Zhao et al., 2011).

However, the effects of large-scale CSPG digestion on ECM remodelling and secondary injury processes in traumatic injuries more relevant to a human spinal cord injury have not been investigated. Here we use a potent LV-ChABC and demonstrate that gene delivery of $\mathrm{ChABC}$ leads to significant neuroprotection and long-term functional repair following spinal contusion injury. We also reveal a novel interaction between CSPG digestion and immune modulation that may underlie this repair.

\section{Materials and Methods}

\section{Chondroitinase gene}

The Proteus vulgaris ChABC gene was modified with mutations targeted to remove five cryptic $N$-glycosylation sites and addition of a mammalian signal sequence and resynthesized with mammalian preferred codons (Muir et al., 2010) to make a mammalian-compatible engineered ChABC gene.

\section{$L V s$}

The modified ChABC cDNA was subcloned into a lentiviral transfer vector (termed LV-ChABC) with the mouse phosphoglycerate kinase (PGK) promoter. The production of this vector is described in detail previously (Zhao et al., 2011). The resulting vector was integrating, selfinactivating, and pseudotyped with VSV-G (vesicular stomatitis virus G). Viral particles were concentrated by ultracentrifugation and titered by a p24 antigen ELISA assay. The viral titer was $479 \mu \mathrm{g} / \mathrm{ml}$ P24, corresponding to $\sim 10^{6}$ transducing units per microliter. A control lentiviral vector (termed LV-GFP) was generated from the same transfer vector containing the cDNA coding for GFP, with a viral titer of $346 \mu \mathrm{g} / \mathrm{ml}$.

\section{Animals}

Adult female Sprague Dawley rats (200-220 g; Harlan Laboratories) were used for all experiments and were housed under a $12 \mathrm{~h}$ light/dark cycle with ad libitum access to food and water. All procedures were performed in accordance with the United Kingdom Animals (Surgical Procedures) Act 1996. Behavioral testing, electrophysiology, and histological analyses were all performed by experimenters blinded to treatment.
Spinal cord injury and intraspinal injections

Comparison of ChABC bacterial enzyme with LV-ChABC. Anesthetized (ketamine, $60 \mathrm{mg} / \mathrm{kg}$, and medetomidine, $0.25 \mathrm{mg} / \mathrm{kg}$ ) adult female Sprague Dawley rats received a midline 150 kdyne spinal contusion injury at spinal level T10/11 using an Infinite Horizon's impactor (Precision Systems Instrumentation). Immediately after contusion injury, rats received intraspinal injections $(2 \times 0.5 \mu \mathrm{l}$, injected at $1 \mathrm{~mm}$ rostral and 1 $\mathrm{mm}$ caudal to the injury site) of either protease-free ChABC enzyme (10 $\mathrm{U} / \mathrm{ml}, n=6$; Seikagaku) or LV-ChABC $(n=6)$. At $3 \mathrm{~d}$ and 2 weeks postinjury, tissue from these animals was taken for biochemical analyses of chondroitin sulfate glycoaminoglycan (CS-GAG) digestion ( $n=3$ per group per time point). An additional cohort received contusion injuries plus intraspinal injections, as above ( $n=4$ per group for LV-ChABC and ChABC enzyme) or intraspinal injection only ( $n=4$ per group for $L V$ ChABC and ChABC enzyme), for histological assessments of CS-GAG digestion in injured and uninjured animals at 8 weeks postsurgery.

Assessing LV-ChABC in long-term functional and histological studies. A larger cohort of animals received moderate thoracic contusion injuries followed by intraspinal injections (as described above) of LV-ChABC or LV-GFP, while an additional control group received no injection (contusion only). These animals underwent behavioral testing for 10 weeks postinjury ( $n=14$ all groups), followed by terminal electrophysiological assessments ( $n=5$ per group) and perfusion for histological assessments ( $n=9$ per group). Contusion injury surgery, functional assessments, and anatomical assessments were performed with the experimenter blinded to treatment group. As all animals achieved comparable baseline scores on the horizontal ladder task, each animal was randomly assigned to a treatment group. Randomization to assign animals to treatment groups was performed by an individual playing no further role in the study, as were intraspinal injections of each treatment. Immediately following contusion injury, all animals were taken to the intraspinal injection surgery station, where they received intraspinal (or no) injections; overlying muscle and skin were then sutured and anesthesia reversed by the individual carrying out the intraspinal injections to ensure the individual carrying out the injury surgery remained blind to treatment group.

Assessing early postinjury changes in inflammation, matrix modification, neuroprotection, and vasculature. A further cohort of animals received moderate thoracic contusion injuries followed by intraspinal injections (as described above) of LV-ChABC or LV-GFP or were uninjured. At $3 \mathrm{~d}$ and 2 weeks postinjury, tissue from these animals was taken for biochemical analyses of inflammatory markers $(n=4$ per group per time point) or immunohistochemistry for inflammatory markers $(n=3$ per group per time point). A further cohort received moderate thoracic contusion injuries followed by intraspinal injections (as described above) of LVChABC or LV-GFP. At 1 week (for NeuN and cleaved caspase-3) or 2 weeks [for CD206, rat endothelial cell antigen (RECA), and vascular endothelial growth factor (VEGF)] postinjury tissue was taken for immunohistochemistry ( $n=3-5$ per group per time point). A final cohort of animals received moderate thoracic contusion injuries (as described above) or were uninjured ( $n=6$ per group). At $7 \mathrm{~d}$ postinjury, tissue was taken for conditioned medium explant studies.

\section{Electrophysiology: conduction of sensory fibers through the injury site}

Axonal conduction was assessed by antidromic stimulation of sensory fibers in the dorsal columns in terminal electrophysiology experiments, as previously described (James et al., 2011). Briefly, the spinal cord was exposed from T7 to L5 (vertebral levels) in urethane-anesthetized rats $(1.25 \mathrm{~g} / \mathrm{kg})$. Antidromic unitary activity was recorded and quantified from teased dorsal root filaments (left and right L3-S1 roots), while first stimulating the entire dorsal column $5 \mathrm{~mm}$ below and then $5 \mathrm{~mm}$ above the injury site. Conduction through the injury site was measured by calculating the number of single units present when stimulating above the injury site as a percentage of the total number of single units when stimulating below. Stimulation was continuous during recording sessions and was performed using 0.2 -ms-duration square-wave pulses at a frequency of $1 \mathrm{~Hz}$ and an incrementally increasing intensity $(0-800 \mu \mathrm{A})$. Stimulation was maximal by $400-500 \mu$ A (i.e., no further unitary activity 
could be recruited), but continued to be increased to $800 \mu \mathrm{A}$ to rule out the possibility of any further, high-threshold fibers.

\section{Behavioral assessments}

Hindlimb function and sensorimotor integration were assessed using the horizontal ladder test. This involved the recording of animals making three runs across a $1 \mathrm{~m}$ horizontal ladder with unevenly spaced rungs. Videos were then analyzed in slow motion to quantify the total number of hindlimb footslips over the course of the three runs, as previously described (James et al., 2011). For assessments of pain sensitivity, mechanical thresholds were determined by measuring latency to withdrawal using an automated electronic Von Frey, where an increasing force $\leq 50$ g over a $20 \mathrm{~s}$ time ramp was applied. Thermal thresholds were determined by measuring latency to nocifensive paw withdrawal from a radiant heat source. Response to a noxious stimulus was also assessed (in the uninjured animals only) by injecting $50 \mu \mathrm{l}$ of $5 \%$ formalin (37\% in sterile saline) subcutaneously into the left forepaw footpad and quantifying the time spent licking or biting the affected paw over $45 \mathrm{~min}$.

\section{Tissue processing and immunohistochemistry}

Animals were deeply anesthetized with sodium pentobarbital (Euthatal, $80 \mathrm{mg} / \mathrm{kg}$, i.p.) and transcardially perfused with $0.9 \%$ saline followed by $4 \%$ paraformaldehyde in $0.1 \mathrm{M}$ phosphate buffer. Immediately after perfusion, lesion site tissue was dissected $(\sim 10 \mathrm{~mm}$ with the lesion epicenter located centrally) as well as lumbar (L3-L6) spinal cord. Tissue was postfixed for $2 \mathrm{~h}$, cryoprotected in $20 \%$ sucrose for $48 \mathrm{~h}$, then embedded and frozen in Optimum Cutting Temperature Compound before being cut into serial $(20 \mu \mathrm{m})$ sections, either cut transversely (for all markers except NF200) or horizontally [for chondroitin-4-sulfate (C-4-S), NF200, and RECA-1 only]. Sections were immunostained using the following primary antibodies: rabbit polyclonal anti-GFAP to label reactive astrocytes (1:2000; DakoCytomation), mouse monoclonal anti-NeuN to label neuronal cell bodies (1:500; Millipore), mouse monoclonal anti-NF200 to label axons (Clone N52, 1:400; Sigma-Aldrich), mouse monoclonal anti-RECA-1 to label endothelial cells (1:200; Abcam), goat polyclonal anti-CD206 to identify M2-type macrophages (Kigerl et al., 2009; 1:100; R\&D Systems), mouse anti-CD68 to identify phagocytic inflammatory cells (1:100; Abcam), rabbit polyclonal anti-5HT to identify serotonergic projections (1:15,000; ImmunoStar), rabbit polyclonal anti-VEGF, a marker of angiogenesis (1:2000; Abcam), rabbit polyclonal anti-cleaved caspase 3, a marker of apoptosis (1:1000; Cell Signaling Technology), and mouse monoclonal anti-C-4-S to reveal digested sugar stub regions (1: 5000; MP Biomedicals). For anti-C-4-S, anti-VEGF, and anti-cleaved caspase 3 staining, tyramide signal amplification was used as described previously (Barritt et al., 2006). Complementary secondary antibodies were donkey anti-mouse Alexa Fluor 488 (1:1000; Invitrogen), donkey anti-rabbit Alexa Fluor 546 (1:1000; Invitrogen), donkey anti-goat Alexa Fluor 488 (1:1000; Invitrogen), and donkey anti-sheep Cy3 (1:100; Jackson ImmunoResearch). Images were acquired using Nikon A1R Si Confocal Imaging system on a Eclipse Ti-E inverted microscope.

\section{Anatomical quantifications}

Cavity size was quantified for $n=4$ per group using a protocol adapted from previously published methods, described in detail in James et al. (2011). Briefly, eriochrome cyanine histochemistry was performed on serial sections through the injury site. For quantification, images were taken of sections at $800 \mu \mathrm{m}$ intervals through the injury site and Axiovision software was used to quantify the total cord area and the cavity area of each section. Cavity area was then calculated as a percentage of total cord area for each section. Using Axiovision software, quantification of $\mathrm{NeuN}+$ cells was performed on 10 sections per animal, spanning $2 \mathrm{~mm}$ through the lesion epicenter (200 $\mu \mathrm{m}$ between sections) and giving a total value of NeuN + cells for all 10 sections combined ( $n=4$ per group for 12 week time point; $n=3$ per group for 1 week time point). Quantification of serotonin (5-HT) and C-4-S intensities was performed in transverse lumbar spinal cord sections $(n=4$ per group, $n=3$ sections per animal). All sections were photographed under the same exposure. For 5-HT, the mean pixel value inside a marked area spanning around the ventral horn was measured for each section. For C-4-S, three areas were marked and measured in each section, giving a mean intensity value for each section, as previously described (Starkey et al., 2012). This analysis was performed using ImageJ (version 1.38; National Institute of Health). Quantification of cleaved caspase- 3 at 1 week postinjury ( $n=5$ per group) was performed by unbiased particle counts following background subtraction (ImageJ software). Images were acquired sequentially using the same exposure parameters. All anatomical quantification was performed by an experimenter blinded to the treatment group.

\section{Electrophoresis and immunoblotting}

For immunoblotting, rats were killed with a lethal injection of sodium pentobarbital and perfused with $150 \mathrm{ml}$ of PBS supplemented with 12.5 mM EDTA to inhibit platelet aggregation and metalloproteinase activity. Spinal cord segments of 5-6 mm were carefully dissected at the T10 level to include the entire injury epicenter. Additional tissue segments from caudal (lumbar) and rostral (cervical spinal cord and cortex) regions were also dissected to assess the rostrocaudal extent of digested CSGAGs. Tissue was weighed and placed on ice-cold PBS, and supplemented with $12.5 \mathrm{~mm}$ EDTA and a broad proteinase inhibitor mixture (P8340, Sigma-Aldrich). Before protein extraction, spinal cord specimens were washed three times with the PBS solution to minimize contamination with plasma proteins. Tissue proteins were then extracted as previously described (Didangelos et al., 2011). Cellular and ECM protein extracts were denatured and reduced in $4 \times$ sample buffer containing 500 mu Tris, pH 6.8, 40\% glycerol, $0.2 \%$ SDS, $2 \% \beta$-mercaptoethanol, and $0.02 \%$ bromophenol blue, and boiled at $98^{\circ} \mathrm{C}$ for $10 \mathrm{~min}$. Twenty-five micrograms of protein per sample were loaded and separated on 15-well, Bis-Tris $10 \%$ polyacrylamide gels (NuPAGE, Invitrogen). Proteins were then transferred on nitrocellulose membranes. Membranes were stained with Ponceau red stain to visualize successful transfer and to confirm equal protein loading, blocked in 5\% fat-free milk powder in PBS, and probed for $16 \mathrm{~h}$ at $4^{\circ} \mathrm{C}$ with different primary antibodies: mouse antiCD68, mouse anti-actin, mouse anti-brevican, mouse anti-neurocan (Abcam), goat anti-CD206 (R\&D Systems), rabbit anti-versican, rabbit anti-aggrecan, (Santa Cruz Biotechnology), rabbit anti-Ibal (Wako), and mouse anti-C-4-S GAG stubs (MP Biomedicals). Antibodies were used at 1:500 dilution in 5\% BSA PBS. Following three washes in PBS Tween 20, membranes were incubated with the appropriate horseradish peroxidase-conjugated secondary antibodies (Dako Cytomation) in 5\% milk powder at 1:2000 dilution for $1 \mathrm{~h}$ at room temperature. Finally, blots were treated with enhanced chemiluminescence (ECL) reagents (GE Healthcare) and films were developed in a Kodak processor. Densitometry of developed blots was performed using ImageJ and values were normalized to $\beta$-actin.

\section{Cell culture and conditioned medium studies}

THP-1 monocytic model cells were used for in vitro culture experiments at passage 3-4. Cells were expanded to 1 million cells per milliliter and kept in DMEM supplemented with 10\% fetal calf serum and penicillin/ streptomycin. Before stimulation, cells were serum starved in plain DMEM for 3-4h. They were then incubated for $24 \mathrm{~h}$ in either spinal cord conditioned medium or left untreated in serum-free medium as indicated. Conditioned medium was generated as follows: contusion-injured ( $7 \mathrm{~d}, n=6)$ or uninjured control animals $(n=6)$ were perfused in sterile PBS containing $12.5 \mathrm{~mm}$ EDTA to minimize plasma contamination. T10 spinal cord segments (5-6 mm, containing the entire injury epicenter or uninjured cord) were carefully dissected using sterile instruments and washed three times in PBS with penicillin/streptomycin antibiotics. Spinal cord explants were then weighed and placed in three weight volumes of either serum-free DMEM $(n=3)$ or in serum-free DMEM supplemented with $0.05 \mathrm{U}$ ChABC $(n=3$; protease-free ChABC, Sigma-Aldrich; $10 \mathrm{U}$ dissolved in DMEM at $100 \mathrm{U} / \mathrm{ml}$ ), to deglycosylate cord CSPGs, and cultured for $24 \mathrm{~h}$ at $37^{\circ} \mathrm{C}$. The conditioned medium from untreated or ChABC-treated explants was then collected, diluted 1:1 in serum-free DMEM, and applied on serum-starved THP-1 cells for $24 \mathrm{~h}$. CD206 mRNA expression was measured using the TaqMan real-time PCR system (Applied Biosystems). RNA was isolated from THP-1 cells and treated with the conditioned medium described above, using a total RNA extraction kit (Omega Bio-Tek). One thousand nanograms of RNA was converted into cDNA using the high-capacity RNA-to-cDNA kit 

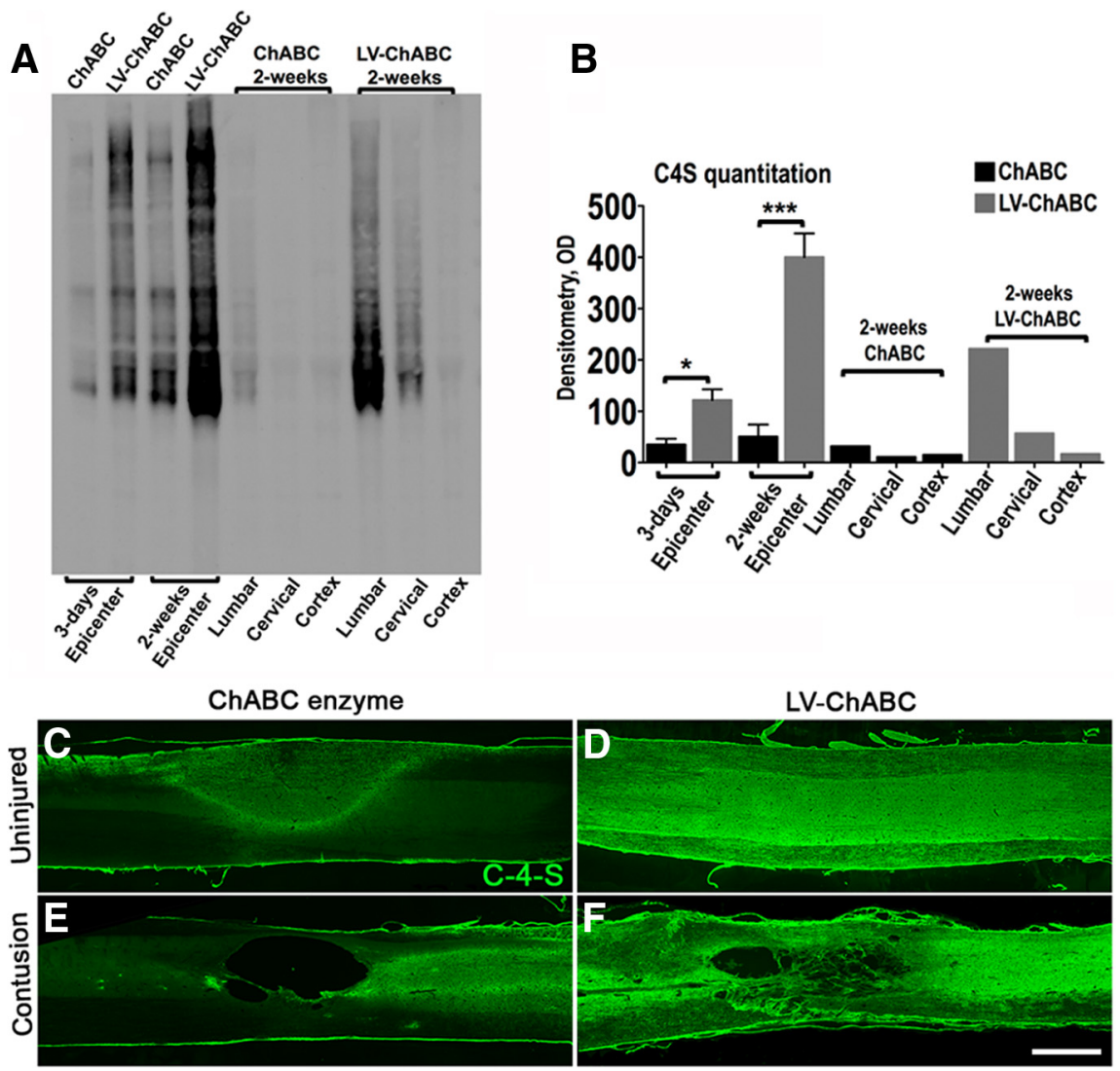

Figure 1. LV delivery of mammalian-compatible engineered ChABC under a PGK promoter leads to large-scale CSPG digestion in the adult mammalian spinal cord; comparison of bacterial ChABC enzyme versus LV-ChABC. $A$, Immunoblotting for C-4-S stubs was used to compare GAG digestion in the injury epicenter (T10) of conventional ChABC enzyme-treated and LV-ChABC-treated cords at $3 \mathrm{~d}$ and 2 weeks following spinal contusion. Lumbar (L2) and cervical (C4) segments as well as brain cortex were also blotted to visualize the spread of $G A G$ digestion at 2 weeks postinjury. $\boldsymbol{B}$, For ChABC and LV-ChABC injury epicenter comparisons, results are mean density values + SEM; $n=3$ cords; ${ }^{*} p<0.05 ;{ }^{* * *} p<0.001$, one-way ANOVA and Bonferroni's multiplecomparison test. For the lumbar, cervical, and cortex, each lane is a pool of extracts derived from three animals. $C-F$, Immunohistochemistry in sagittal sections through the uninjured $(\boldsymbol{C}, \boldsymbol{D})$ or the injured $(\boldsymbol{E}, \boldsymbol{F})$ thoracic spinal cord showing the $\mathbf{C}-4-\boldsymbol{S}$ (green) digestion pattern at 8 weeks postinjection with or without contusion injury. In uninjured spinal cords, weak C-4-S immunoreactivity restricted to the injection zone was apparent 8 weeks following injection of bacterial $\mathrm{ChABC}(\boldsymbol{C})$, compared with intense and widespread C-4-S immunoreactivity with LV-ChABC injection (D). Abundant CSPG digestion was also observed at the injury epicenter 8 weeks following contusion and LV-ChABC injection, and the lesion site appeared to be associated with numerous tissue bridges $(\boldsymbol{F})$. By comparison, the injury epicenter following intraspinal injection of conventional $\mathrm{ChABC}$ enzyme contained lower levels of digested CSPGs at 8 weeks postinjury and the epicenter had developed into a large cavity $(\boldsymbol{E})$. These data suggest that large-scale CSPG digestion achieved by LV-ChABC may have a neuroprotective effect. Scale bar: (in $\boldsymbol{F}) \mathbf{C}-\boldsymbol{F}, 1 \mathrm{~mm}$.

(Applied Biosystems). Ten nanograms of RNA/reaction was quantified using a human cd206 TaqMan prevalidated primer/probe mix (Hs00267207_m1), at a concentration of $900 \mathrm{~nm}$ for the primer and 200 $\mathrm{nm}$ for the probe. Real-time PCR was performed using an automated Roche thermocycler. Data analysis was performed using the $\Delta \Delta \mathrm{Ct}$ method, where the transcript levels of CD206 in conditioned-mediumtreated cells were compared with CD206 expression in untreated, control cells. Eukaryotic 18s ribosomal RNA (Hs99999901_s1) served as the housekeeping gene to normalize levels of CD206 expression. All samples were measured in duplicate. For CD206 protein levels, THP-1 cells were treated with the same conditioned medium described above. Following $24 \mathrm{~h}$ stimulation, the cells were lysed in $0.2 \%$ SDS and $25 \mu \mathrm{g}$ of protein per sample were immunoblotted with antibodies against CD206, as described above. For CD206 immunostaining, THP-1 cells were fixed in $2 \%$ paraformaldehyde for $15 \mathrm{~min}$, blocked in 5\% donkey serum, and immunostained with goat anti-CD206 (1:100; R\&D Systems) antibodies followed by Alexa Fluor 488 donkey anti-goat (1:500) secondary antibodies. Nuclei were counterstained with DAPI.
Statistical analyses

All numerical values are reported as mean \pm SEM and all statistical analyses were performed using GraphPad Prism v5 software. Behavioral data were analyzed by two-way repeatedmeasures (RM) ANOVA, while histological, immunoblot, and electrophysiological data were analyzed by one-way ANOVA in instances of multiple comparisons and by unpaired Student's $t$ test in instances of single comparisons. Post hoc comparisons were performed where appropriate; all statistical tests are stated in the text.

\section{Results}

LV delivery of mammalian-compatible engineered ChABC under a PGK promoter leads to large-scale CSPG digestion in the adult mammalian spinal cord

To assess efficacy of ChABC gene delivery, we first assessed the extent of CSPG digestion that could be achieved with an LV-expressing mammalian-compatible ChABC driven by a PGK promotor (LV-ChABC), compared with conventional ChABC bacterial enzyme, following intraspinal injection into uninjured or contused adult rat spinal cords (Fig. 1). Extent and rostrocaudal spread of CSPG digestion was quantified with Western blot analyses of tissue homogenates from the injury epicenter and from caudal (lumbar cord) and rostral (cervical cord and cortex) regions at two postinjury time points ( $3 \mathrm{~d}$ and 2 weeks) following contusion and intraspinal injection (Fig. $1 A, B$ ). This revealed abundant C-4-S stubs (indicating CS-GAG digestion) at the injury epicenter at $3 \mathrm{~d}$ postinjury following $\mathrm{LV}$ ChABC injection, which increased further by 2 weeks postinjury. By comparison, much lower levels of C-4-S were achieved with injections of ChABC bacterial enzyme (C-4-S levels were significantly higher at both time points following LVChABC compared with bacterial ChABC; $p<0.05$ and $p<0.001$, respectively, oneway ANOVA, Bonferroni's post hoc; Fig. $1 A, B)$. In addition to causing more potent CSPG digestion at the T10 injury epicenter, LV-ChABC also led to more widespread CSPG digestion, with abundant C-4-S in the lumbar spinal cord and, to a lesser extent, the cervical spinal cord, but negligible C-4-S expression in brain cortex. C-4-S levels were negligible in all rostrocaudal regions with $\mathrm{ChABC}$ bacterial enzyme injections, indicating that treatment was restricted to the epicenter only (Fig. $1 A, B$ ). Thus, gene delivery of mammalian-compatible ChABC leads to more intense and widespread CSPG digestion in the adult mammalian spinal cord than with conventional ChABC bacterial enzyme.

CSPG digestion was also examined in histological sections at a later ( 8 week) time point following intraspinal injection of LVChABC or ChABC bacterial enzyme in uninjured and contused animals (Fig. $1 C-F$ ). Eight weeks after intraspinal injection, there was still evidence of digested CSPGs in the spinal cord. However, 

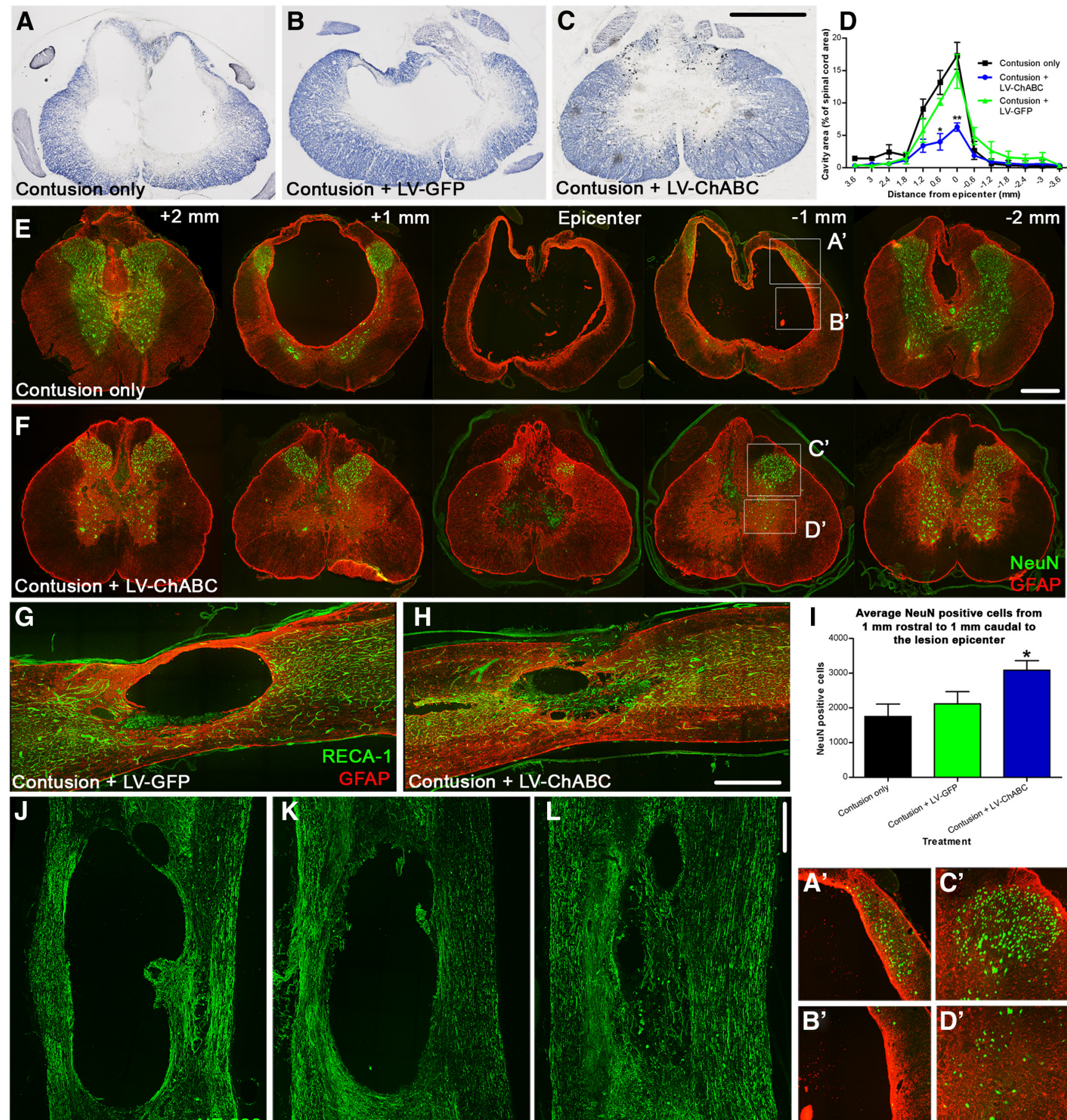

Contusion only
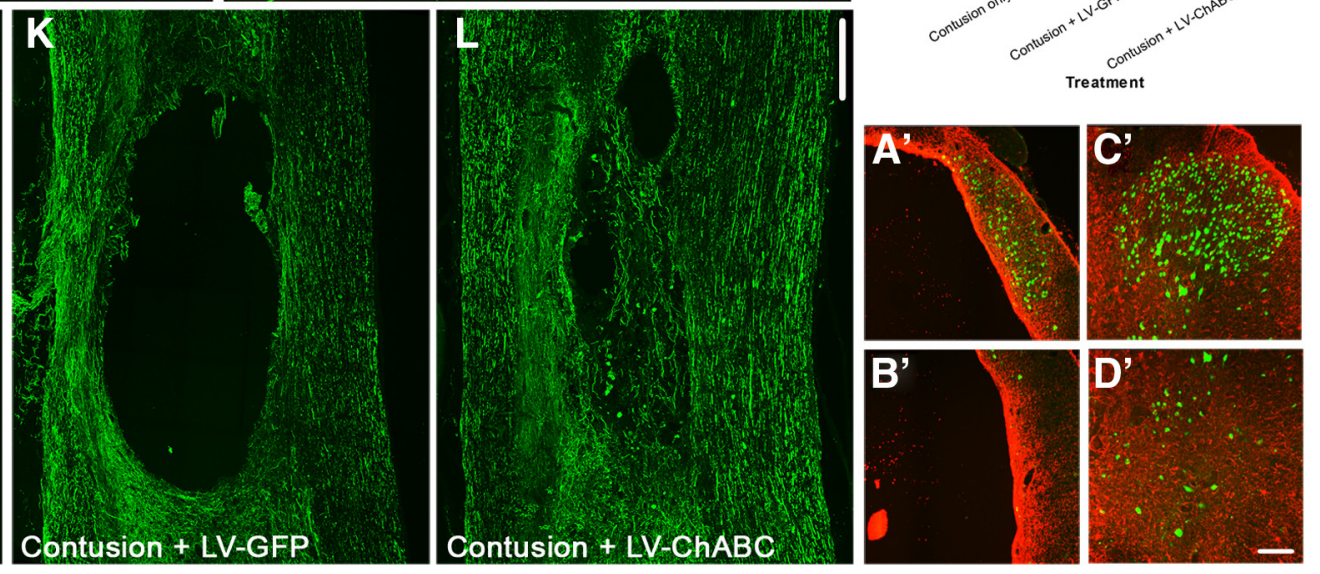

Figure 2. Gene delivery of ChABC leads to improved injury pathology and neuroprotection following spinal contusion. $A-C$, Eriochrome cyanine histochemistry in transverse spinal cord sections 12 weeks following spinal contusion shows a marked reduction in cavity formation at the lesion epicenter following LV-ChABC treatment $(C)$, compared with contusion only ( $A$ ) or LV-GFP treatment (B).D, Quantification of cavity area reveals a significant reduction in cavity size at the epicenter following LV-ChABC treatment as well as in the rostrocaudal spread of the cavity (asterisks indicate a significant difference compared with both contusion only and contusion plus LV-GFP; $p<0.05,2$-way repeated-measures ANOVA, Bonferroni's posthoc). $E, F$, Merged images of GFAP (astrocytes, red) and NeuN (neurons, green) immunoreactivity throughout the rostrocaudal axis. Dramatic changes in reactive gliosis and neuronal cell survival after contusion injury and LV-ChABC treatment $(\boldsymbol{F})$ compared with contusion-only controls $(\boldsymbol{E})$ were observed. $\boldsymbol{I}$, Quantification of averaged NeuN-positive cells counted over a series of sections from $1 \mathrm{~mm}$ rostral to $1 \mathrm{~mm}$ caudal to the epicenter revealed a significant preservation of spinal neurons following LV-ChABC treatment, compared with contusion only and LV-GFP treatment; ${ }^{*} p<0.05$, one-way ANOVA, Tukey's post hoc. G, $\boldsymbol{H}$, The much reduced lesion epicenter in LV-ChABC-treated spinal cord contains numerous blood vessels, indicated by RECA-1 immunoreactivity (green). J-L, While large cystic cavities are apparent in chronically injured spinal cords (12 weeks postinjury) that are untreated or received LV-GFP treatment, numerous NF 200-positive axons (green) are apparent coursing through the lesion epicenter in LV-ChABC-treated spinal cords. $\boldsymbol{A}^{\prime}-\boldsymbol{D}^{\prime}$, High-magnification images of the areas indicated in $\boldsymbol{E}$ and $\boldsymbol{F}$. Scale bars: (in $\boldsymbol{C}$ ) $\boldsymbol{A}-\boldsymbol{C}, 500 \mu \mathrm{m}$; (in $\left.\boldsymbol{E}\right) \boldsymbol{E}, \boldsymbol{F}, 500 \mu \mathrm{m} ; \boldsymbol{H}, 500 \mu \mathrm{m}$; (in $\boldsymbol{L}$ ) $J-L, 500 \mu \mathrm{m}$; (in D') $A^{\prime}-D^{\prime}, 100 \mu \mathrm{m}$. 
in naive animals injected with $\mathrm{ChABC}$ bacterial enzyme, C-4-S immunoreactivity was low and was restricted to a central zone around the injection site (Fig. 1C), whereas intense and more widely distributed C-4-S stub immunoreactivity was apparent in the spinal cords of animals injected with LV-ChABC 8 weeks after injection, indicating sustained and widespread delivery of active enzyme with LV-ChABC (Fig. 1D). Similar intense C-4-S immunoreactivity was apparent at 8 weeks in animals that received intraspinal injection of LV-ChABC immediately following spinal contusion (Fig. $1 F$ ) and again C-4-S expression was much lower and less widespread in contused animals injected with ChABC bacterial enzyme (Fig. $1 E$ ). Interestingly, abundant CSPG digestion in the injury epicenter at early postinjury time points (Fig. $1 A, B)$ appeared to be associated with evidence of tissue preservation at 8 weeks postinjury in this initial histological analysis, with smaller cavities and many tissue bridges apparent in LVChABC-injected animals (Fig. $1 F$ ). Conversely, following bacterial ChABC injection, where levels of digested CSPGs were much lower within the epicenter at early postinjury time points (Fig. $1 A, B$ ), large cavities had formed at the injury epicenter 8 weeks after contusion injury (Fig. 1E). These data provide initial evidence that large-scale CSPG digestion achieved by LV-ChABC may lead to reduced secondary injury pathology following spinal contusion injury.

\section{Gene delivery of ChABC leads to reduced secondary injury} pathology following spinal cord injury

Potential neuroprotective effects of large-scale CSPG digestion were investigated in more detail by examining whether LVChABC could reduce the progressive pathology that occurs following spinal contusion, and that is largely responsible for the permanent loss of function (Schwab and Bartholdi, 1996). Animals received thoracic contusion injuries and intraspinal injections of either LV-ChABC or a control GFP-expressing LV (LV-GFP) or no injection (contusion only). Stereological quantification of eriochrome cyanine staining in serial sections from $3.6 \mathrm{~mm}$ rostral to $3.6 \mathrm{~mm}$ caudal to the injury epicenter at a chronic (12 weeks) postinjury time point revealed a remarkable reduction in cavity size apparent at the lesion epicenter following LV-ChABC treatment ( $1 \mu \mathrm{l}$ injected at the time of injury), compared with untreated or LV-GFP-treated animals (Fig. $2 A-C$ ) and significantly reduced spread of cavitation ( $p<0.01$ two-way repeated-measures ANOVA; Fig. 2D). Since contusion injury leads to mass destruction of spinal gray matter, extensive neuronal cell loss typically occurs along the rostrocaudal extent of the injury, with the lesion epicenter characteristically devoid of spinal neurons. While we observed this pattern in untreated (Fig. 2E, A' and B') and LV-GFP-treated animals at 12 weeks following spinal contusion, many neuronal cell bodies were apparent at the injury epicenter and in rostrocaudal spinal segments following LVChABC treatment, corresponding to areas of reduced pathology and cavitation (Fig. 2F, C' and D'), revealed by GFAP and NeuN immunohistochemistry in serial sections through the injury. Quantification of the number of surviving spinal neurons (summed total cell counts in 10 serial sections from $1 \mathrm{~mm}$ rostral to $1 \mathrm{~mm}$ caudal to the epicenter) revealed a significant $\sim 50 \%$ increase in the number of spinal neurons surviving the trauma following LV-ChABC treatment, compared with contusion only and contusion plus LV-GFP (3084 $\pm 273,1750 \pm 359$, and $2014 \pm 353 \mathrm{NeuN}$-positive cells, respectively; $p<0.05$; oneway ANOVA, Tukey's post hoc; Fig. 2I). Additionally, we noted altered reactive gliosis after LV-ChABC treatment, where GFAPpositive astrocytic processes appeared more diffuse and elon-
A

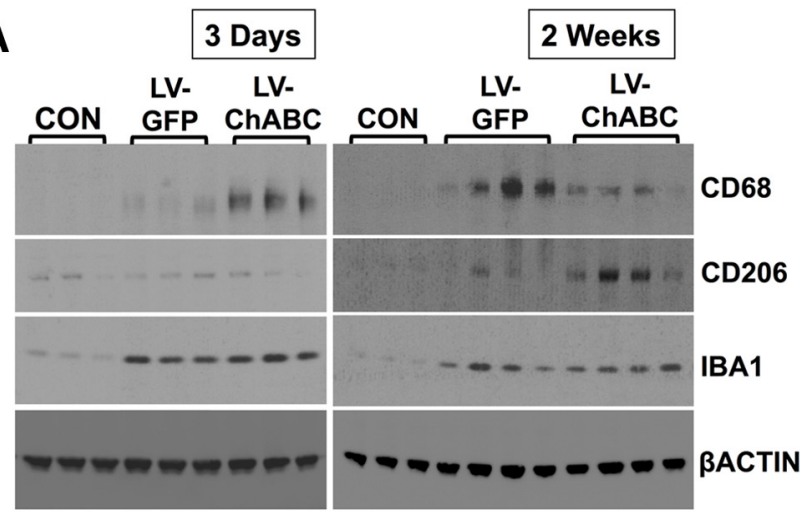

B
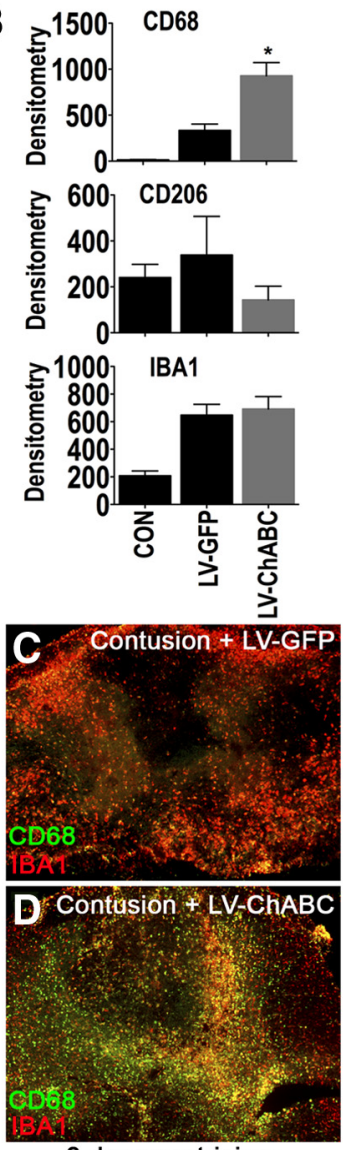

3 days post-injury
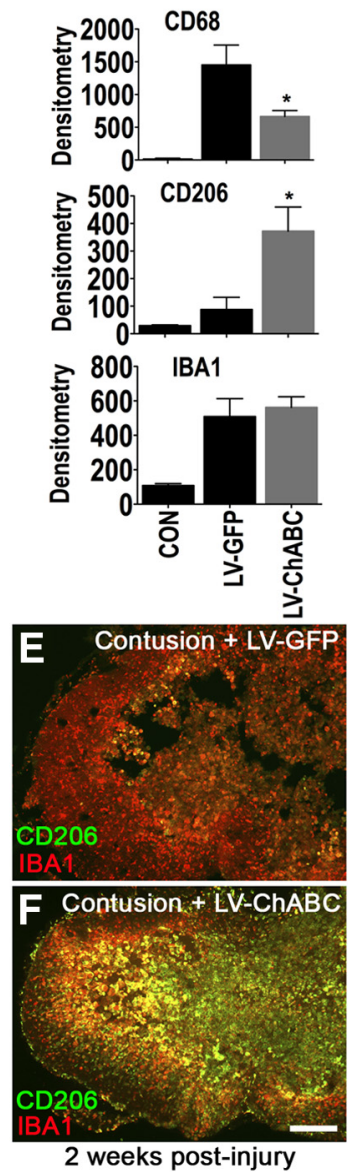

Figure 3. Gene delivery of $\mathrm{ChABC}$ leads to alterations in macrophage markers. $A, B$, Immunoblotting for $\mathrm{CD68}$, $\mathrm{CD} 206$, and IBA1 in the injury epicenter of either LV-GFP-treated or LVChABC-treated cords $3 \mathrm{~d}$ and 2 weeks following spinal contusion (samples from individual animals are shown in each lane). Uninjured, control (CON) T10 spinal cord tissue was used for comparison. Values were normalized to $\beta$-actin. Results are mean density values $+\mathrm{SEM} ; n=$ $3-4$ cords; ${ }^{*} p<0.05$; one-way ANOVA and Bonferroni's multiple-comparison test. $\mathbf{C}-\boldsymbol{F}$, Double labeling of either CD68 or CD206 (green) with IBA1 (red) shows an early increase in CD68 immunostaining in the injury epicenter $3 \mathrm{~d}$ after contusion and LV-ChABC injection (D) followed by increased CD206 immunostaining at 2 weeks $(\boldsymbol{F})$, compared with LV-GFP $(\boldsymbol{C}, \boldsymbol{E})$. Scale bar: (in $\boldsymbol{F}) \mathbf{C}-\boldsymbol{F}, 500 \mu \mathrm{m}$.

gated, compared with the thick border of reactive astrocytes typically observed around the cavity borders following contusion only or treatment with control LV-GFP (Fig. 2, compare GFAP immunoreactivity in $E, F$ epicenter). To ascertain whether tissue at the epicenter was viable and contained axonal projections, we examined vasculature with RECA-1 (an endothelial cell marker) and spinal axons with NF200 (an axonal marker) immunohisto- 
chemistry in longitudinal sections through the injury site. Confocal images of contused spinal cords at the lesion epicenter following no treatment or after LVGFP or LV-ChABC delivery revealed that the much reduced lesion epicenter was well vascularized following $\mathrm{LV}-\mathrm{ChABC}$ treatment, with numerous blood vessels apparent through the lesion core (Fig. $2 G, H)$. Furthermore, NF200-positive axons were abundant in the lesion epicenter following LV-ChABC treatment (Fig. 2L), in stark contrast to the axon-free large cavities in untreated or LV-GFP-treated contused spinal cords (Fig. $2 \mathrm{~J}, \mathrm{~K}$ ). Thus, a single administration of LV-ChABC at the time of injury prevented much of the hallmark secondary pathology that is typically observed in chronic spinal cord-injured tissue.

\section{Gene delivery of $\mathrm{ChABC}$ induces}

macrophage, vascular, and ECM changes following spinal cord injury

Local and infiltrating macrophages are key effectors of tissue remodelling and repair following injury. Therefore, since our data indicated that gene delivery of ChABC led to a significant improvement in tissue preservation (Fig. 2), we assessed whether LV-ChABC treatment could alter macrophage responses in vivo following spinal contusion. Immunoblotting was used to characterize macrophage phenotypic properties in the lesion epicenter at $3 \mathrm{~d}$ and 2 weeks following spinal contusion and intraspinal injection of $\mathrm{LV}-\mathrm{ChABC}$ or LV-GFP, in comparison with uninjured tissue (Fig. 3A,B). The phagolysosomal marker CD68 was significantly increased in LV-ChABC-treated cords $3 \mathrm{~d}$ postinjury compared with LV-GFP-treated animals, whereas at 2 weeks post injury, CD68 was significantly reduced in LV-

ChABC-treated cords, which instead showed a significant upregulation of $\mathrm{CD} 206$, the main marker of alternative (M2) macrophage activation (all comparisons $p<0.05$ one-way ANOVA, Bonferroni's post hoc; Fig. 3A,B). IBA1 levels were comparable in LV-GFP and LV-ChABC treatments (both being increased compared with uninjured controls; Fig. $3 A, B$ ), indicating that overall microglia/macrophage numbers were similar and that LV-ChABC specifically affects macrophage phenotype.

Immunohistochemical analyses on a further set of animals confirmed the early ( $3 \mathrm{~d}$ ) increase in CD68-positive cells in LVChABC-injected cords (Fig. $3 C, D$ ) followed by an increase in CD206-positive cells at 2 weeks postinjury (Fig. 3 E, F), compared with LV-GFP-injected cords, with overall comparable macrophage/microglia staining (IBA1 immunostaining) within the lesion epicenter with both treatments (Fig. 3C-F). CD206 and IBA1 double immunofluorescence revealed areas of clear colocalization as well as areas of confined single staining for CD206 in the lesion epicenter (Fig. $3 E, F$ ). This suggests either differential activation of microglia/macrophages in the epicenter or an infiltrating origin of the CD206-positive cells.

In support of the in vivo findings, conditioned medium sampled from injured T10 spinal cord explants cultured ex vivo induced the expression of CD206 protein on resting THP-1 cells (a simple model of unpolarized and undifferentiated monocytes). CD206 expression was further increased with conditioned medium from ChABC-treated explants (Fig. $4 A, B$; $p<0.05$ oneway ANOVA, Bonferroni's post hoc). In contrast, conditioned medium sampled from uninjured T10 explants did not induce CD206 expression with or without ChABC treatment (Fig. $4 A, B)$. The effect of ChABC-treated explant conditioned medium on the upregulation of CD206 was confirmed at the mRNA level (Fig. 4C; $p<0.05$ one-way ANOVA, Bonferroni's post hoc). Finally, immunofluorescence highlighted the low baseline expression of CD206 on the unpolarized monocytic cells and confirmed its upregulation following treatment with injured cord conditioned medium, which was further enhanced in cells stimulated with ChABC-treated injured cord 

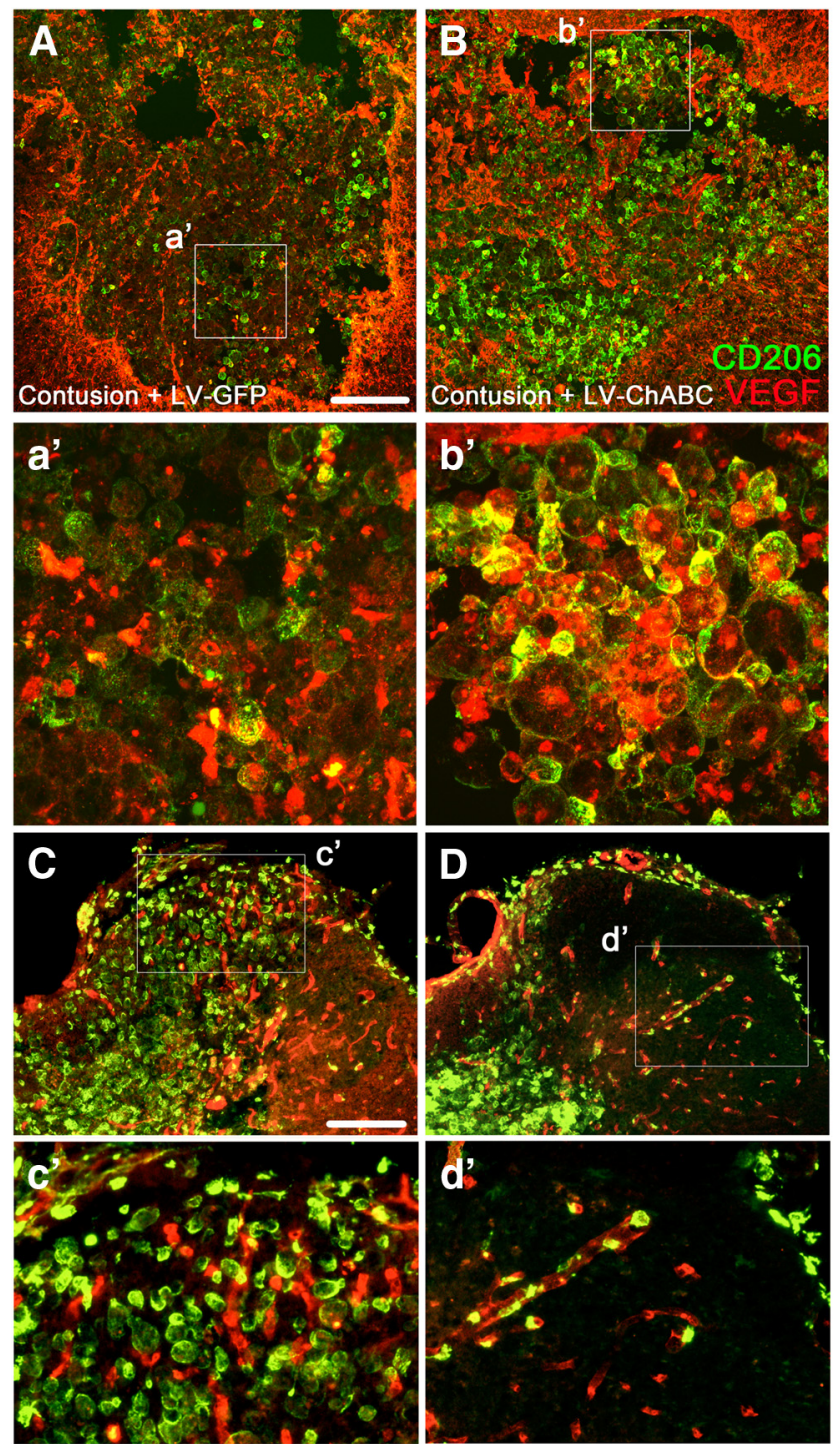

Figure 5. CD206-positive macrophages are closely associated with improved vascularity. $A_{\text {, }}$ $B$, At 2 weeks postinjury, the numerous (D206-positive cells (green) in the injury epicenter of LV-ChABC-treated cords were closely associated with VEGF (red), compared with LV-GFPtreated cords where few CD206-positive cells were observed in the epicenter and VEGF was concentrated mainly around the lesion border (boxed areas shown at high magnification in $\boldsymbol{a}^{\prime}$ and $\boldsymbol{b}$ ). LV-ChABC-treated cords were also double stained for CD206 (green) and the endothelial cell marker RECA-1 (red), revealing CD206-positive areas that were highly vascularized in the injury epicenter ( $\boldsymbol{C}$ and $\boldsymbol{c}$ 'high magnification) and perilesional and meningeal blood vessels which contained CD206-positive cells at sites more distal to the injury ( $\boldsymbol{D}$ and $\boldsymbol{d}^{\prime}$ high magnification). Scale bars: (in $\boldsymbol{A}) \boldsymbol{A}, \boldsymbol{B}, 200 \mu \mathrm{m}$; (in $\boldsymbol{C}) \boldsymbol{C}, \boldsymbol{D}, 200 \mu \mathrm{m}$.

conditioned medium (Fig. 4D). These data indicate that the expression of CD206 is mediated by soluble factor(s) present in the injury site and underlines the role of the proteoglycan matrix in their regulation.

To look at potential vascular changes following LV-ChABC treatment, double immunostaining in 2-week-postinjury tissue revealed that the numerous CD206-positive cells in the lesion epicenter of LV-ChABC-treated cords were closely associated with VEGF, a key angiogenic cytokine (Fig. $5 B, b$ '). This association was less pronounced in LV-GFP-treated animals, which instead showed few CD206-positive macrophages and lower levels of VEGF in the lesion epicenter, but strong VEGF staining within the thick astroglial lesion border (Fig. 5A, $a^{\prime}$ ). In LV-ChABCtreated animals, CD206-positive cells were also closely associated with numerous RECA-1-positive blood vessels in the lesion epicenter (Fig. $5 C, c^{\prime}$ ), consistent with the well established angiogenic properties of M2 macrophages. However, at sites more proximal to the injury epicenter, CD206-positive cells were also apparent in the meninges and clearly within RECA-1-positive blood vessels (Fig. $5 D, d^{\prime}$ ), indicating a potential infiltrating origin of the cells.

Since changes in the inflammatory response could have a neuroprotective function, we also performed immunostaining for neuronal cell bodies at an early (7 d) postinjury time point (Fig. $6 A, B)$. LV-ChABC-treated cords showed a significant increase in NeuN-positive cells through the lesion site $(p<0.05$; unpaired two-tailed Student's $t$ test; Fig. $6 E$ ). The increased neuronal survival in LV-ChABC-treated animals was accompanied by a significant reduction in the expression of cleaved (activated) caspase-3, a critical mediator of apoptosis, in the injury epicenter $(p<0.05$; unpaired two-tailed Student's $t$ test; Fig. $6 C, D, F)$. Accordingly, there was a clear negative correlation $(r=-0.82$, Spearman correlation coefficient), between NeuN counts and cleaved caspase-3 in the injury epicenter of LV-GFP-treated and LV-ChABC-treated cords.

We also examined changes in ECM proteins following largescale CSPG digestion. CSPG levels in the injury epicenter were examined by immunoblotting at $3 \mathrm{~d}$ and 2 weeks following spinal contusion and intraspinal injection of LV-ChABC or LV-GFP compared with tissue from uninjured animals (Fig. $7 A, B$ ). LVChABC treatment had a differential effect on the protein levels of aggrecan and versican at 2 weeks postinjury, with aggrecan significantly increased and versican significantly decreased in the epicenter of LV-ChABC-injected cords, compared with LV-GFPinjected cords (Fig. $7 A, B$ ). Brevican was significantly increased at $3 \mathrm{~d}$ only, while neurocan was unaffected by the treatment (Fig. $7 A, B)$. Versican has been previously shown to be upregulated in human M1 macrophages polarized in vitro (Martinez et al., 2006) and has been implicated in classical inflammatory activation via TLR2 (Kim et al., 2009). Therefore the decrease in versican, coupled with the increase in CD206 observed in LV-ChABC-treated cords, supports the hypothesis that ChABC activity (confirmed by C-4-S immunoblotting; Fig. 7A) promotes alternative macrophage activation after injury.

\section{Gene delivery of $\mathrm{ChABC}$ leads to improved sensorimotor} function and spinal conduction following spinal cord injury We also examined whether LV-ChABC could improve long-term functional outcome following spinal contusion. Force readouts from individual animals confirmed consistent reproducible injuries across all experimental groups (Fig. 8A). Functional effects were assessed using the horizontal ladder test, a skilled motor task requiring fine sensorimotor integration, and this revealed clear differences between the treatment groups (Fig. $8 B$ ). While both control groups (contusion only and contusion plus LV-GFP treatment) were severely and significantly impaired throughout the testing period, making many footslip errors as they traversed the ladder, LV-ChABC-treated animals showed a markedly improved recovery of function. Improved function was observed as early as 1 week postinjury $(33.1 \pm 3.5$ footslip errors for LVChABC compared with $48.8 \pm 3.5$ and $47.1 \pm 3.9$ for LV-GFP and contusion only, respectively; Fig. $8 B$ ), in line with the histological observations of neuroprotection 1 week following LV-ChABC treatment. Importantly, improved function in LVChABC-treated animals was sustained into chronic stages postinjury (footslip errors at 10 weeks postinjury: $14.6 \pm 1.6,28.3 \pm 2.8$, $29.7 \pm 3$ for LV-ChABC, LV-GFP, and contusion only, respectively), with LV-ChABC-treated rats showing significantly fewer 
footslip errors compared with both control groups throughout the testing period $(p<0.01$ at all postinjury time points; two-way repeated-measures ANOVA, Bonferroni's post hoc; Fig. 8B).

We then used electrophysiology to assess whether LV-ChABC could lead to improved conduction of spinal axons following contusion injury (Fig. $8 C, D$ ). Axonal conduction in long-distance sensory projections in the spinal cord is severely and chronically impaired in this injury model, with only a small percentage of axons capable of conducting through the injury site (James et al., 2011). Single-unit recordings of dorsal column axons activated antidromically above and below the T10 contusion site at 10 weeks postinjury revealed a significant effect of LV-ChABC treatment on restoring sensory fiber conduction, with the percentage of fibers capable of conducting across the contusion injury significantly increased in LV-ChABC animals compared with animals with contusion only or contusion plus LV-GFP (23.1 $\pm 2.9 \%$, compared with $10.4 \pm 0.6 \%$ and $11.3 \pm 2 \%$, respectively; $p<0.01$ one-way ANOVA, Tukey's post hoc; Fig. $8 C$ ). Thus, a single administration of LV-ChABC at the time of injury led to improved conduction of spinal axons at a chronic postinjury time point following spinal contusion.

Gene delivery of ChABC leads to increased density of descending serotonergic projections following spinal cord injury

Since a well known consequence of digesting CSPGs with ChABC is to enhance axonal sprouting, we determined whether large-scale CSPG digestion following LVChABC treatment would lead to increased serotonergic input onto targets caudal to the injury. Serotonin (5-HT) immunohistochemistry was examined in the ventral horn of the lumbar spinal cord 10 weeks following contusion and intraspinal injection. Dense serotonergic innervation was apparent in the ventral horn of LV-ChABCtreated animals, in contrast to low 5-HTimmunoreactivity in the ventral horn of animals with contusion only or contusion plus LV-GFP (Fig. 9A-C), with a significant increase in serotonergic fiber density (mean 5 -HT pixel intensity values of $122.2 \pm 13.1$ compared with $67.03 \pm 12.7$ and $74.13 \pm$ 9.1, respectively; $p<0.05$ one-way ANOVA; Fig. 9D). Corresponding to increased serotonergic input, we observed intense C-4-S immunoreactivity in the lumbar spinal cord of LV-ChABCtreated animals, which was absent in contusion-only or GFPtreated animals (C-4-S mean pixel intensity, $41.35 \pm 8.35$, compared with $4.28 \pm 0.53$ and $4.86 \pm 1.36$, respectively; $p<$ 0.001 one-way ANOVA; Fig. 9E-G). These findings suggest the injury epicenter.
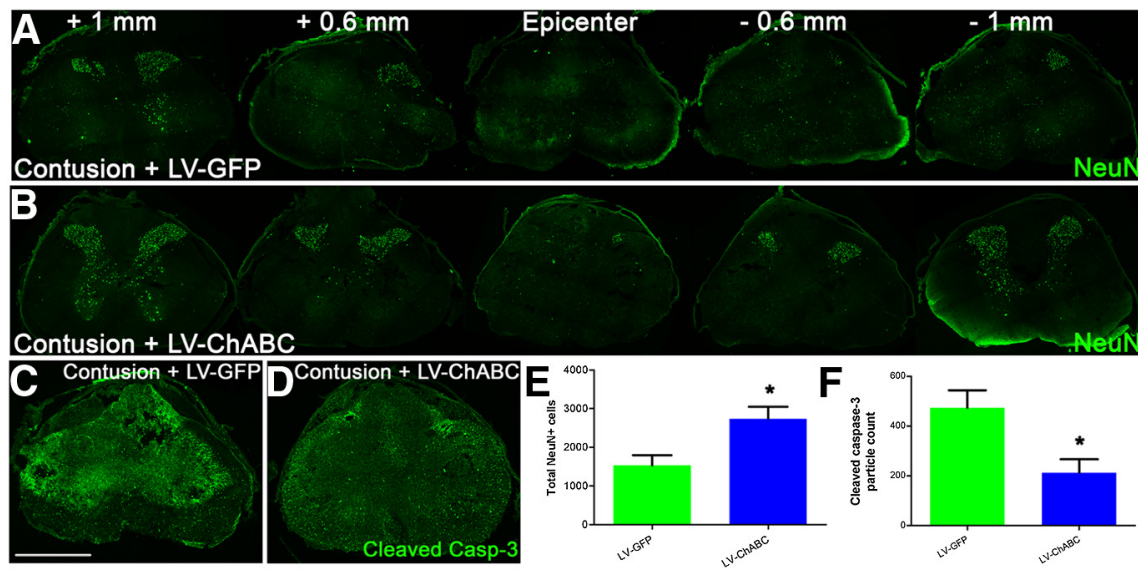

Figure 6. Gene delivery of $\mathrm{ChABC}$ leads to reduced neuronal death associated with lower levels of apoptosis at 1 week postinjury. $A, B$, Serial images of NeuN (neurons, green) immunoreactivity throughout the rostrocaudal axis showing greater survival of spinal neurons at 1 week postinjury following LV-ChABC treatment, compared with LV-GFP treatment. C, $\boldsymbol{D}$, Cleaved caspase-3 immunoreactivity in the lesion epicenter reveals a clear reduction in the apoptotic marker at 1 week postinjury following $\mathrm{LV}$-ChABC treatment, compared with LV-GFP treatment. $\boldsymbol{E}$, Quantification of total NeuN-positive cells counted in serial sections from $1 \mathrm{~mm}$ rostral to $1 \mathrm{~mm}$ caudal to the epicenter revealed a significant preservation of spinal neurons following LV-ChABC treatment, compared with contusion only and LV-GFP treatment; ${ }^{*} p<0.05$, unpaired two-tailed Student's $s$ test. $F$, Quantification of cleaved caspase-3 activity in the lesion epicenter revealed reduced levels of apoptosis following LV-ChABC treatment, compared with LV-GFP controls; ${ }^{*} p<0.05$, unpaired two-tailed Student's $t$ test. Scale bar: (in C) $A-D, 500 \mu \mathrm{m}$.
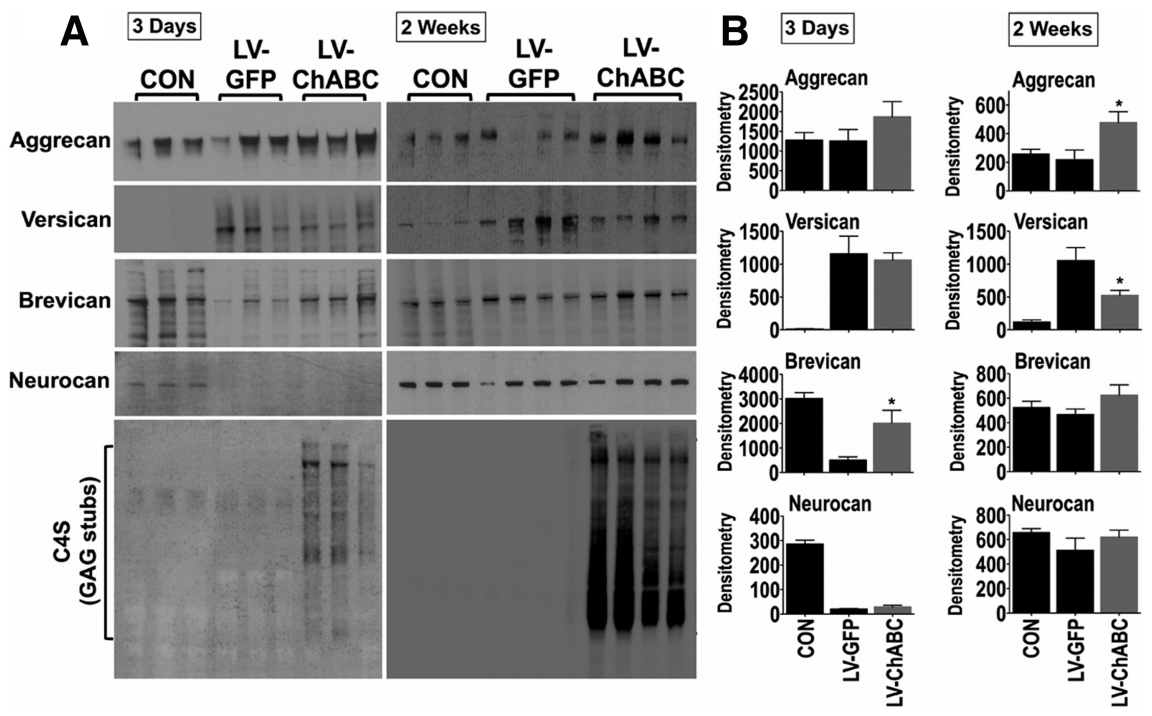

Figure 7. Gene delivery of ChABC promotes remodelling of specific CSPGs following spinal contusion. $A$, Immunoblotting for aggrecan, versican, brevican, and neurocan in the injury epicenter of either LV-GFP-treated or LV-ChABC-treated cords at $3 \mathrm{~d}$ and 2 weeks following spinal contusion (samples from individual animals are shown in each lane). Uninjured, control (CON) T10 spinal cord tissue was used for comparison. A switch in the expression of specific CSPGs was observed, with increased aggrecan and decreased versican apparent at 2 weeks postinjury following LV-ChABC treatment, compared with LV-GFP treatment. $\boldsymbol{B}$, Protein levels were estimated by densitometry. Results are mean density values $+\mathrm{SEM} ; n=4$ cords; ${ }^{*} p<0.05$; one-way ANOVA and Bonferroni's multiple-comparison test. Immunoblotting against the C-4-SGAG stubs demonstrates LV-ChABC enzymatic activity in

that widespread CSPG digestion achieved with LV-ChABC can promote changes in serotonergic fiber density, below the level of a spinal cord injury.

The potential for large-scale CSPG digestion to promote sprouting and novel connectivity could potentially lead to detrimental consequences, such as enhanced pain. We therefore performed behavioral assessments to determine withdrawal thresholds to thermal and mechanical stimulation of the paw and to monitor pain behavior following formalin injection (Fig. 10). 

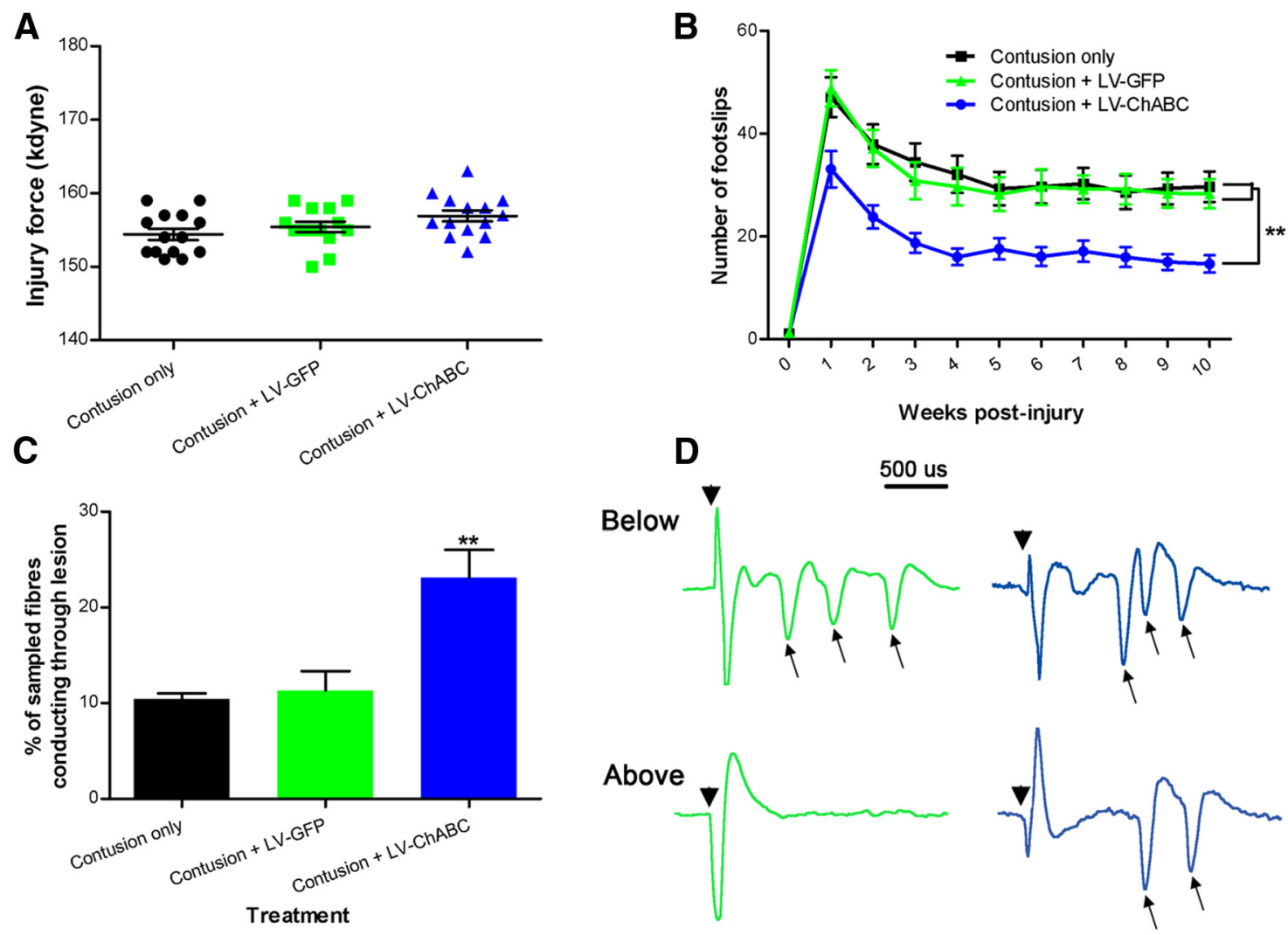

Figure 8. Gene delivery of ChABC leads to improved sensorimotor function and spinal conduction following spinal contusion. $A$, Impact data showing the actual force applied to individual animals was within $10 \%$ of the intended force of 150 kdyne and mean values for each group were not significantly different ( $n=14$ per group; $p>0.05 ; 1$-way ANOVA), confirming that any group differences were not due to differences in the impact force during surgery. $\boldsymbol{B}$, Treatment with LV-ChABC leads to an early and sustained improvement in sensorimotor function, as shown by a significant reduction in footslips on the horizontal ladder task at all postinjury time points compared with contusion only and contusion plus LV-GFP treatment; $p<0.01$, two-way repeatedmeasures ANOVA, Bonferroni's post hoc). C, Following treatment with LV-ChABC, there is a significant improvement in the percentage of sensory dorsal column axons that are capable of conducting through the injury site at a chronic (10 weeks) postinjury time point ( $p<0.01$, 1-way ANOVA, Tukey's post hoc). D, Example traces of recordings.

There were no significant differences observed in paw withdrawal thresholds or in response duration to the painful stimulus between LV-ChABC-treated and control-treated groups; this was apparent in both uninjured (Fig. 10A-D) and injured (Fig. $10 E, F$ ) animals. These data provide evidence that longterm CSPG digestion does not lead to enhanced pain sensitivity.

\section{Discussion}

Here we demonstrate that gene delivery of mammalian-compatible ChABC leads to large-scale digestion of CSPGs in the spinal cord, which results in neuroprotection and long-term improved functional outcome following spinal contusion injury. Moreover, we reveal a direct association between CSPG digestion and modulation of macrophage phenotype to favor alternatively activated M2 macrophages, whose ability to promote resolution of inflammation, positive tissue remodelling, and angiogenesis provides a mechanism underlying the tissue sparing and neuroprotection observed following ChABC gene delivery.

\section{Large-scale CSPG digestion with ChABC gene delivery}

Large-scale expression of ChABC has not previously been shown. Due to issues of enzyme stability, ChABC has typically been administered via repeated bolus injections into indwelling catheters placed intrathecally at the lesion site (Bradbury et al., 2002; Caggiano et al., 2005; Iaci et al., 2007; García-Alías et al., 2009) or in the intracerebroventricular system (Carter et al., 2008, 2011; Starkey et al., 2012). Thermostablizing the enzyme can prolong the activity of ChABC and effectively reduce CSPG levels at lesion boundaries for 6 weeks following one administration (Lee et al., 2010), although delivery remains restricted to the injection site. Here we show efficient delivery of active enzyme for at least 3 months after LV-ChABC delivery and that $\mathrm{ChABC}$ delivery is widespread, with digested CSPGs apparent over several spinal segments spanning the injury epicenter, and as far caudal as the lumbosacral spinal cord. These findings indicate stable and long-term expression of the transgene and widespread secretion of active ChABC enzyme following intraspinal injection of LV-ChABC.

While there is much evidence that intraparenchymal injections of regular ChABC bacterial enzyme can lead to functional improvements in partial injury models (Pizzorusso et al., 2002; Massey et al., 2006; Cafferty et al., 2008; Hunanyan et al., 2010; Alilain et al., 2011; Bowes et al., 2012), they have not been so effective in more traumatic injury models, such as compression or contusion injury where minimal or no improvements in function have been observed following localized intraparenchymal injections (Iseda et al., 2008; Tom et al., 2009b; Harris et al., 2010; Jakeman et al., 2011). The current study supports the hypothesis that in clinically relevant traumatic models, where secondary damage and inflammation is more severe, sustained delivery leading to large-scale CSPG digestion is necessary, and this can be achieved by LV-ChABC. 

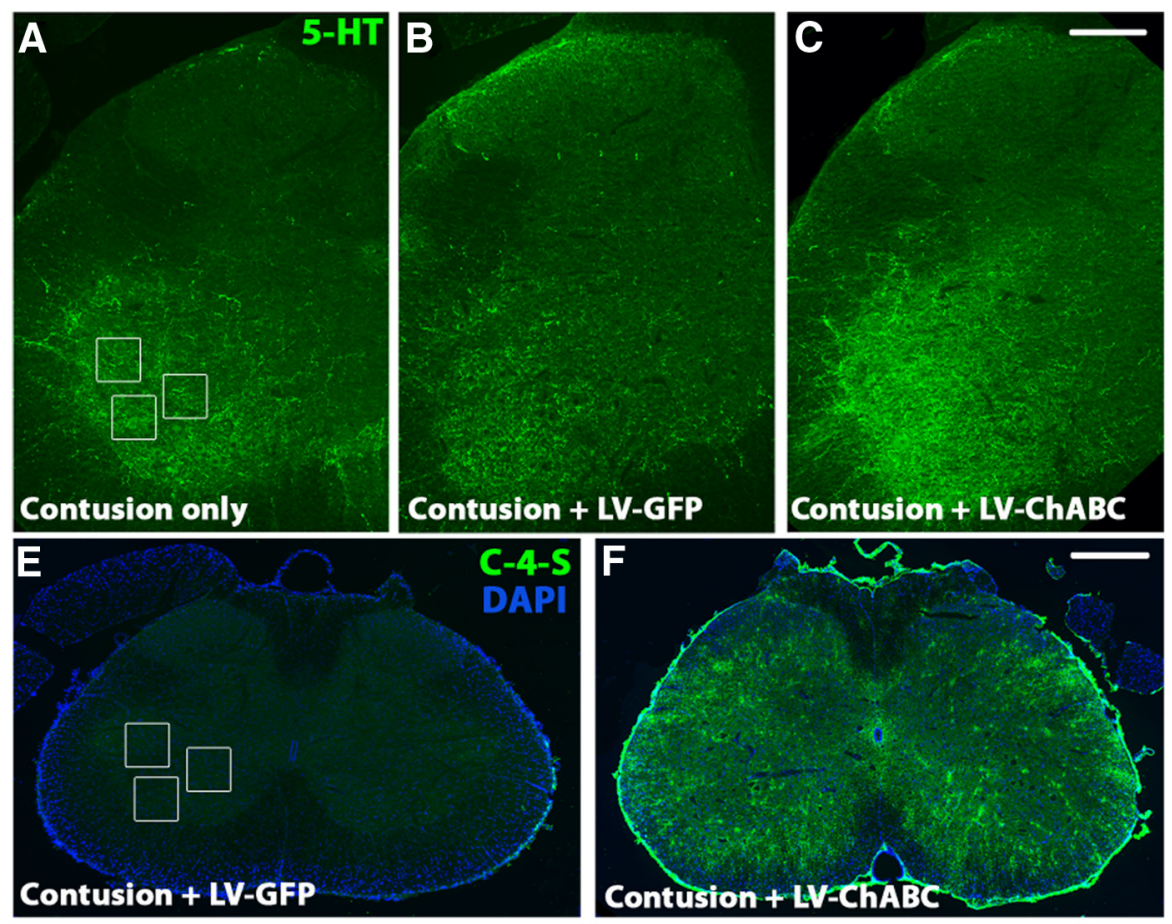
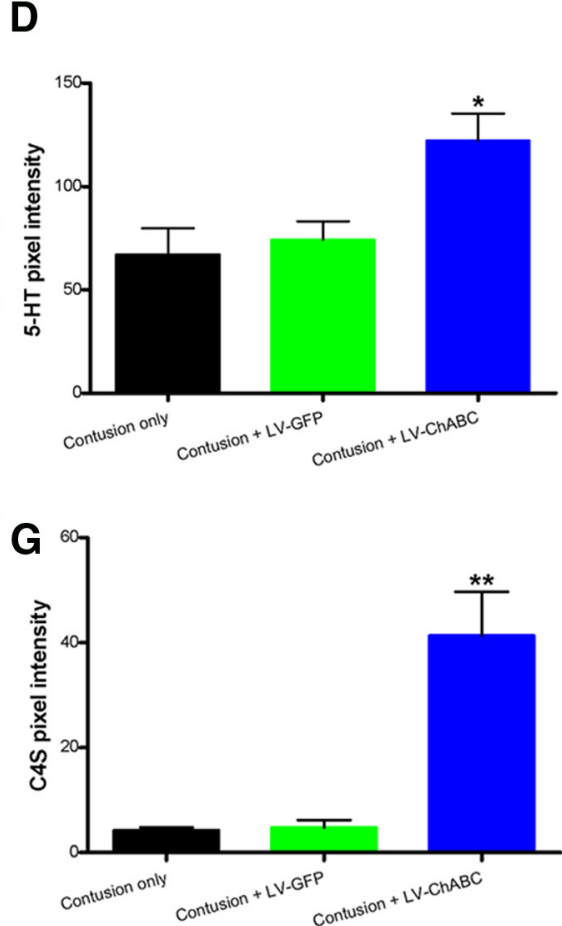

Figure 9. Gene delivery of ChABC leads to increased serotonergic innervation following spinal contusion. $\boldsymbol{A}-\boldsymbol{D}$, Serotonergic (5-HT) fiber density is significantly enhanced in the ventral horn of the lumbar spinal cord following treatment with LV-ChABC $(\boldsymbol{C})$ compared with contusion only $(\boldsymbol{A})$ and LV-GFP (B; quantified in $\boldsymbol{D} ; n=4$ per group; $p<0.05,1$-way ANOVA, Tukey's post hoc). $\boldsymbol{E}-\mathbf{G}, \mathbf{C}-4-S$ immunoreactivity is abundant in the lumbar cord of LV-ChABC-treated animals $(\boldsymbol{F})$, but absent in both LV-GFP and contusion-only animals $(\boldsymbol{E} ;$ quantified in $\boldsymbol{G} ; n=4$ per group; $p<0.001,1$-way ANOVA, Tukey's post hoc); boxes in $\boldsymbol{A}$ and $\boldsymbol{E}$ show regions where intensity measurements were quantified. Scale bar: (in $\boldsymbol{C}$ ) $\boldsymbol{A}-\boldsymbol{C}, 250 \mu \mathrm{m}$; (in $\boldsymbol{F}$ ) $\boldsymbol{E}, \boldsymbol{F}, 500 \mu \mathrm{m}$.

\section{Improved function with $\mathrm{Ch} \mathrm{ABC}$ gene delivery}

The functional consequences of large-scale CSPG digestion have not previously been assessed. Here we saw a significant and sustained recovery on the horizontal ladder test following LVChABC treatment, which is likely due to early neuroprotective effects since these animals never reached the same level of impairment as the other groups on this task, despite an injury of the same severity. This is in line with our histological observations of neuroprotection and reduced apoptosis at 1 week postinjury and long-term tissue preservation following LV-ChABC treatment. The observed improvement in conduction of dorsal column axons through the injury site at a chronic postinjury time point is also likely to be due primarily to the significant sparing of spinal tissue following treatment with LV-ChABC, although we cannot rule out the possibility that there may have been some regeneration of dorsal column axons that could also account for improved conduction. Alleviation of conduction block is also likely to be a contributing factor, since CSPGs have previously been shown to block conduction following spinal cord injury (Hunanyan et al., 2010). A further potential contributing factor to improved axonal conduction is enhanced remyelination, since ChABC has previously been shown to increase the recruitment of oligodendrocyte precursor cells (Siebert et al., 2011) and M2 polarization has recently been shown to play an essential role in CNS remyelination (Miron et al., 2013).

\section{Proteoglycan and macrophage modulation by $\mathrm{ChABC}$ gene delivery}

The local inflammatory response following spinal cord injury is known to be neurotoxic and inhibitory to regeneration (Silver and Miller, 2004). Previous work has shown that classically activated M1 macrophages are rapidly induced and maintained at sites of traumatic spinal cord injury, followed by a smaller and transient M2 macrophage response (Kigerl et al., 2009; David and Kroner, 2011). In vitro and in vivo evidence suggests that M1 macrophages are neurotoxic (Kigerl et al., 2009) while M2 macrophages promote resolution of inflammation, angiogenesis, and tissue remodelling and exhibit enhanced phagocytic properties following injury (Mantovani et al., 2002). Polarizing macrophages toward an M2 phenotype may therefore limit secondary inflammatory-mediated injury (Kigerl et al., 2009). In this study we showed that LV-ChABC treatment induced expression of CD206, a well characterized marker of M2 macrophage polarization, in macrophages in the lesion epicenter at 2 weeks postinjury. Moreover, our data indicate that the upregulation of CD206 is mediated by a soluble factor(s) present in the injury penumbra, since conditioned medium derived from ex vivo injured cord explants was able to induce CD206 on resting THP-1 monocytic cells and this was enhanced by $\mathrm{ChABC}$ activity. The upregulation of CD206 in LV-ChABC-treated cords was preceded by an early and transient increase in CD68, a lysosomal protein whose expression and post-translational modification is increased in actively phagocytic macrophages (Damoiseaux et al., 1994; da Silva and Gordon, 1999). Early phagocytosis of apoptotic cells and myelin debris could enhance repair and correlates well with the tissue preservation and neuroprotection that we observed in LVChABC-treated cords. In support of this hypothesis, Boven et al. (2006) showed that myelin ingestion by macrophages in multiple sclerosis lesions is associated with upregulation of CD206, M2 polarization, and increased immunoregulatory activity.

CD206-positive macrophages in LV-ChABC-treated tissue were not always associated with IBA1 immunostaining, indicating that these cells were not exclusively derived from local activated microglia. Accordingly, we found CD206-positive cells 

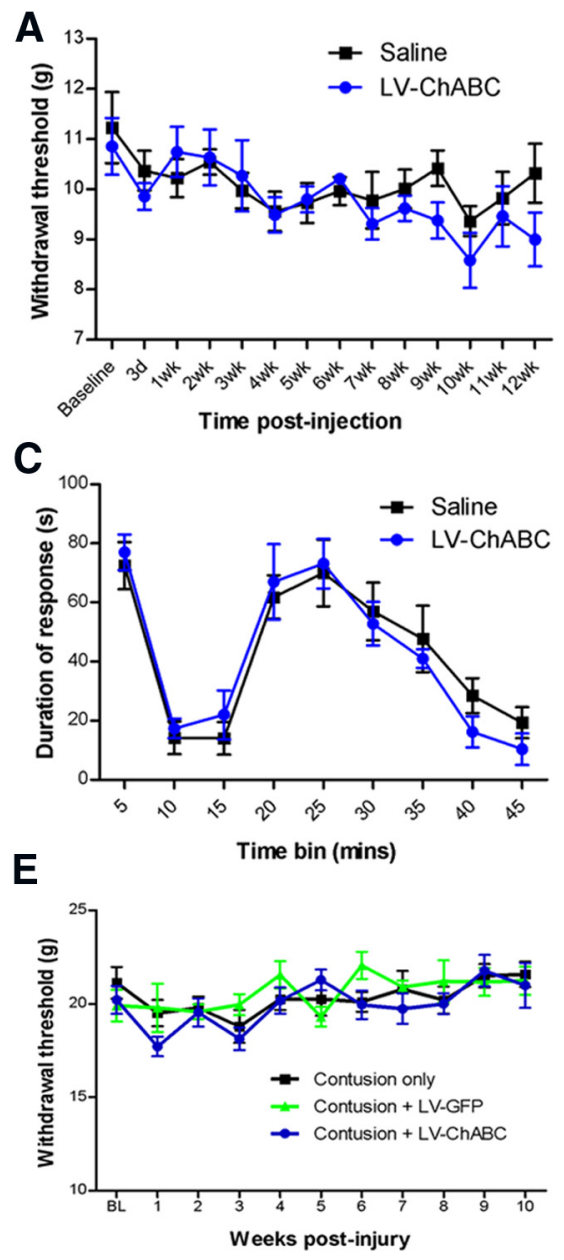

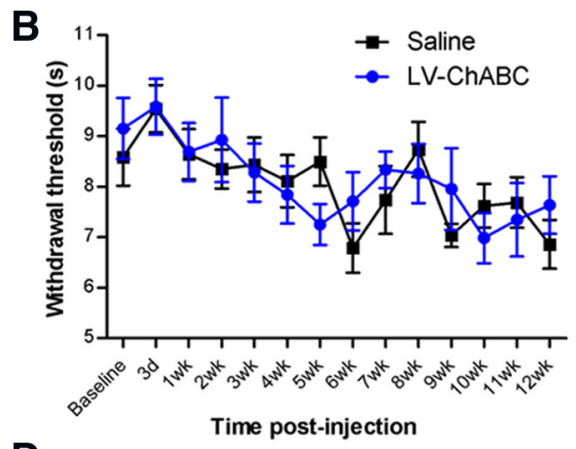

D

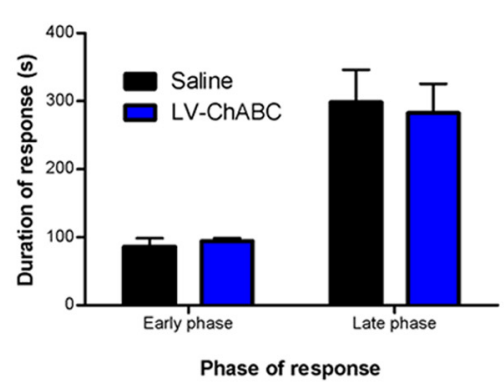

$\mathbf{F}$

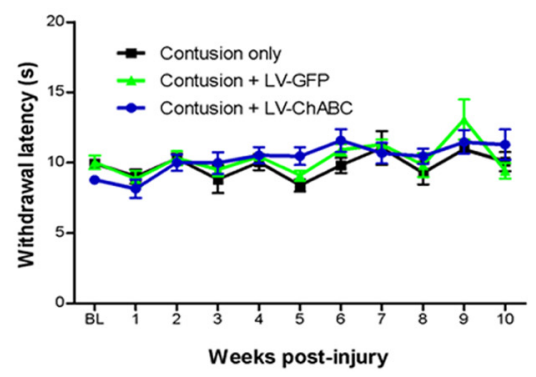

Figure 10. Long-term CSPG digestion does not lead to an enhanced pain state in uninjured animals or following spinal contusion. $\boldsymbol{A}, \boldsymbol{B}$, Assessments of withdrawal thresholds to mechanical (von Frey test; $\boldsymbol{A}$ ) or thermal (Hargreaves test; $\boldsymbol{B}$ ) stimulation of the forepaw following injection of saline or LV-ChABC into the $C 5$ spinal cord revealed no significant changes in pain sensitivity over a 12 week time course. $\boldsymbol{C}, \boldsymbol{D}$, Injection of formalin to elicit a pain response in uninjured animals resulted in typical biphasic licking and biting behaviors in the affected forepaw, with no significant differences observed between groups during the early or late phases of the formalin-evoked response, indicating no enhanced sensitivity to pain following long-term treatment with LV-ChABC ( $n=$ 7-8 per group; $p>0.05$ 2-way repeated-measures ANOVA for time course data and Student's $t$ test for early-phase and latephase data). $\boldsymbol{E}, \boldsymbol{F}$, Assessments of withdrawal thresholds to mechanical (von Frey test; $\boldsymbol{E}$ ) or thermal (Hargreaves test; $\boldsymbol{F}$ ) stimulation of the hindpaw following $\mathrm{T} 10$ spinal contusion and injection of LV-GFP or LV-ChABC at the injury site revealed no significant changes in pain sensitivity over a 10 week time course $(n=7-8$ per group; $p>0.052$-way repeated-measures ANOVA).

associated with blood vessels in the lesion epicenter, penumbra, and meninges, suggesting that they may originate from the circulation. Moreover, these cells could also promote angiogenesis, a well known feature of alternative activation (Sica and Mantovani, 2012). To this end, we found that CD206-positive cells in the injury epicenter of LV-ChABC-treated cords were closely associated with VEGF, a central angiogenic mediator. Interestingly, Shechter et al. (2013) recently demonstrated that infiltrating monocyte-derived macrophages enhanced tissue recovery and repair following spinal cord injury in mice and that these trafficking monocytes have M2 phenotypic characteristics. Similarly, Evans et al. (2014) showed that the majority of accumulating cells in murine dorsal column crush lesions are circulation derived.

Altered glial scar formation was also observed following LVChABC treatment, with more diffuse, elongated astrocytic processes observed around the lesion penumbra, in contrast to the thick border of astrogliosis apparent in control tissue, and typically observed around cavity edges following spinal contusion (James et al., 2011). Interestingly, the potential of CSPGs to di- rectly influence reactive astrogliosis and support a heightened state of microglial activation and chronic inflammation has recently been demonstrated in the microenvironment of brain tumors (Silver et al., 2013). Additionally, CSPG degradation products released upon $\mathrm{ChABC}$ treatment might play a role in influencing inflammatory or other cells, since free CS-GAGs have previously been shown to repolarize retinal ganglion cells and nerve fibers within the retinal neuroepithelium (Brittis and Silver, 1994) and free CS disaccharides can be neuroprotective in inflammation-induced neuropathologies (Rolls et al., 2006).

Versican was rapidly induced in the lesion epicenter after spinal contusion, but levels were significantly reduced in LVChABC-treated cords 2 weeks postinjury. Versican has been previously shown to accumulate in spinal injury lesions and is believed to be inhibitory to axon growth (Jones et al., 2003). Recent evidence suggests that versican plays a role in macrophage regulation since versican fragments have been shown to activate macrophages via toll-like receptor 2 (Kim et al., 2009), which is especially abundant in M1 macrophages (Mantovani et al., 2002) and involved in classical activation (Monaco et al., 2009). Additionally, versican has been used as a marker of M1 polarization in human monocytes activated in vitro by IFN $\gamma$ and LPS (Martinez et al., 2006). Moreover, concomitant with the decrease in versican, we observed an increase in aggrecan following LV-ChABC treatment. Aggrecan has previously been implicated in neuroprotection, since neurons associated with aggrecan-based perineuronal nets are protected against tau pathology in Alzheimer's disease (Morawski et al., 2010). Thus, the differential expression of versican and aggrecan, known to be involved in M1 polarization and neuroprotection, respectively, supports our findings for positive ECM remodeling and tissue repair following ChABC gene delivery.

\section{Enhanced serotonergic innervation following ChABC gene delivery}

While the findings of immune cell modulation following LVChABC treatment were unpredicted, we observed expected effects on descending fiber sprouting, since a well known consequence of CSPG digestion is to enhance anatomical sprouting and plasticity (for review, see Kwok et al., 2012; Bartus et al., 2012; Burnside and Bradbury, 2014). Serotonergic projections to the ventral horn are important for locomotor function (Saruhashi et al., 1996) and our observations of enhanced serotonergic innervation caudal to the injury are in agreement with previous studies using ChABC (Barritt et al., 2006; Karimi-Abdolrezaee et al., 2010) or other plasticity-enhancing therapeutics (Li et al., 2005; McKillop et al., 2013). However, the neuroprotective effects of 
LV-ChABC may also have contributed to the serotonergic fiber increase, since tissue preservation at the epicenter will likely have spared some descending serotonergic projections. These findings suggest that widespread CSPG digestion can promote changes in serotonergic fiber density, whether by axonal sparing, fiber sprouting, or both, at sites distal to the injury. Widespread CSPG digestion may also be important for the immunomodulatory effects of LV-ChABC, since activated macrophages typically spread over several spinal segments following contusion injury (David and Kroner, 2011), likely requiring treatment of a large area to elicit significant macrophage modulation.

The efficacy of LV-ChABC, along with alternative strategies to modify scar-associated molecules, such as microtubule stabilization (Hellal et al., 2011) and direct targeting of specific CSPG epitopes (Brown et al., 2012), highlights the importance of targeting the ECM to promote repair following spinal cord injury. There are a number of possible issues to consider in terms of LV-ChABC development toward a clinical therapeutic, including the risk of insertional mutagenesis posed by integrating LVs, as has been reported for other retroviral vectors (Hacein-Bey-Abina et al., 2003). However, no such effect has been so far observed in the primate CNS (Jarraya et al., 2009) or in on-going clinical trials (Palfi et al., 2014). Additionally, although previous studies have found no enhanced pain sensitivity following ChABC treatment (Barritt et al., 2006; Galtrey et al., 2007; Karimi-Abdolrezaee et al., 2010) and in the present study LV-ChABC did not lead to enhanced sensitivity to noxious or non-noxious stimuli up to 12 weeks post-treatment, we do not know whether longer-term large-scale CSPG digestion could eventually have detrimental effects. Therefore, it would be optimal to regulate ChABC gene expression, for example by using an LV with an inducible promoter (Blesch et al., 2005; Sooksawate et al., 2013).

Thus, using a gene delivery vector-based approach that enables resident $\mathrm{CNS}$ cells to stably secrete $\mathrm{ChABC}$ in vivo, we demonstrate potent effects on reducing secondary injury pathology and restoring function in a clinically relevant model of traumatic spinal contusion. Furthermore, these improvements are associated with remodelling of matrix molecules and modulation of the immune response. These findings have widespread implications for the treatment of spinal injuries and other pathological disease states.

\section{References}

Alilain WJ, Horn KP, Hu H, Dick TE, Silver J (2011) Functional regeneration of respiratory pathways after spinal cord injury. Nature 475:196-200. CrossRef Medline

Barritt AW, Davies M, Marchand F, Hartley R, Grist J, Yip P, McMahon SB, Bradbury EJ (2006) Chondroitinase ABC promotes sprouting of intact and injured spinal systems after spinal cord injury. J Neurosci 26:1085610867. CrossRef Medline

Bartus K, James ND, Bosch KD, Bradbury EJ (2012) Chondroitin sulphate proteoglycans: key modulators of spinal cord and brain plasticity. Exp Neurol 235:5-17. CrossRef Medline

Blesch A, Conner J, Pfeifer A, Gasmi M, Ramirez A, Britton W, Alfa R, Verma I, Tuszynski MH (2005) Regulated lentiviral NGF gene transfer controls rescue of medial septal cholinergic neurons. Mol Ther 11:916-925. CrossRef Medline

Boven LA, Van Meurs M, Van Zwam M, Wierenga-Wolf A, Hintzen RQ, Boot RG, Aerts JM, Amor S, Nieuwenhuis EE, Laman JD (2006) Myelinladen macrophages are anti-inflammatory, consistent with foam cells in multiple sclerosis. Brain 129:517-526. Medline

Bowes C, Massey JM, Burish M, Cerkevich CM, Kaas JH (2012) Chondroitinase $\mathrm{ABC}$ promotes selective reactivation of somatosensory cortex in squirrel monkeys after a cervical dorsal column lesion. Proc Natl Acad Sci U S A 109:2595-2600. CrossRef Medline
Bradbury EJ, McMahon SB (2006) Spinal cord repair strategies: why do they work? Nat Rev Neurosci 7:644-653. CrossRef Medline

Bradbury EJ, Moon LD, Popat RJ, King VR, Bennett GS, Patel PN, Fawcett JW, McMahon SB (2002) Chondroitinase ABC promotes functional recovery after spinal cord injury. Nature 416:636-640. CrossRef Medline

Brittis PA, Silver J (1994) Exogenous glycosaminoglycans induce complete inversion of retinal ganglion cell bodies and their axons within the retinal neuroepithelium. Proc Natl Acad Sci U S A 91:7539-7542. CrossRef Medline

Brown JM, Xia J, Zhuang B, Cho KS, Rogers CJ, Gama CI, Rawat M, Tully SE, Uetani N, Mason DE, Tremblay ML, Peters EC, Habuchi O, Chen DF, Hsieh-Wilson LC (2012) A sulfated carbohydrate epitope inhibits axon regeneration after injury. Proc Natl Acad Sci U S A 109:4768-4773. CrossRef Medline

Burnside ER, Bradbury EJ (2014) Review: manipulating the extracellular matrix and its role in brain and spinal cord plasticity and repair. Neuropathol Appl Neurobiol 40:26-59. CrossRef Medline

Cafferty WB, Yang SH, Duffy PJ, Li S, Strittmatter SM (2007) Functional axonal regeneration through astrocytic scar genetically modified to digest chondroitin sulfate proteoglycans. J Neurosci 27:2176-2185. CrossRef Medline

Cafferty WB, Bradbury EJ, Lidierth M, Jones M, Duffy PJ, Pezet S, McMahon SB (2008) Chondroitinase ABC-mediated plasticity of spinal sensory function. J Neurosci 28:11998-12009. CrossRef Medline

Caggiano AO, Zimber MP, Ganguly A, Blight AR, Gruskin EA (2005) Chondroitinase $\mathrm{ABCI}$ improves locomotion and bladder function following contusion injury of the rat spinal cord. J Neurotrauma 22:226-239. CrossRef Medline

Carter LM, Starkey ML, Akrimi SF, Davies M, McMahon SB, Bradbury EJ (2008) The yellow fluorescent protein (YFP-H) mouse reveals neuroprotection as a novel mechanism underlying chondroitinase $\mathrm{ABC}$-mediated repair after spinal cord injury. J Neurosci 28:14107-14120. CrossRef Medline

Carter LM, McMahon SB, Bradbury EJ (2011) Delayed treatment with chondroitinase $\mathrm{ABC}$ reverses chronic atrophy of rubrospinal neurons following spinal cord injury. Exp Neurol 228:149-156. CrossRef Medline

Carulli D, Laabs T, Geller HM, Fawcett JW (2005) Chondroitin sulfate proteoglycans in neural development and regeneration. Curr Opin Neurobiol 15:116-120. CrossRef Medline

Curinga GM, Snow DM, Mashburn C, Kohler K, Thobaben R, Caggiano AO, Smith GM (2007) Mammalian-produced chondroitinase AC mitigates axon inhibition by chondroitin sulfate proteoglycans. J Neurochem 102: 275-288. CrossRef Medline

Damoiseaux JG, Döpp EA, Calame W, Chao D, MacPherson GG, Dijkstra CD (1994) Rat macrophage lysosomal membrane antigen recognized by monoclonal antibody ED1. Immunology 83:140-147. Medline

da Silva RP, Gordon S (1999) Phagocytosis stimulates alternative glycosylation of macrosialin (mouse CD68), a macrophage-specific endosomal protein. Biochem J 338:687-694. CrossRef Medline

David S, Kroner A (2011) Repertoire of microglial and macrophage responses after spinal cord injury. Nat Rev Neurosci 12:388-399. CrossRef Medline

Didangelos A, Yin X, Mandal K, Saje A, Smith A, Xu Q, Jahangiri M, Mayr M (2011) Extracellular matrix composition and remodeling in human abdominal aortic aneurysms: a proteomics approach. Mol Cell Proteomics 10:M111. CrossRef Medline

Evans TA, Barkauskas DS, Myers JT, Hare EG, You JQ, Ransohoff RM, Huang AY, Silver J (2014) High-resolution intravital imaging reveals that blood-derived macrophages but not resident microglia facilitate secondary axonal dieback in traumatic spinal cord injury. Exp Neurol 254C:109120. CrossRef Medline

Galtrey CM, Asher RA, Nothias F, Fawcett JW (2007) Promoting plasticity in the spinal cord with chondroitinase improves functional recovery after peripheral nerve repair. Brain 130:926-939. Medline

García-Alías G, Barkhuysen S, Buckle M, Fawcett JW (2009) Chondroitinase $\mathrm{ABC}$ treatment opens a window of opportunity for task-specific rehabilitation. Nat Neurosci 12:1145-1151. CrossRef Medline

Hacein-Bey-Abina S, von Kalle C, Schmidt M, Le Deist F, Wulffraat N, McIntyre E, Radford I, Villeval JL, Fraser CC, Cavazzana-Calvo M, Fischer A (2003) A serious adverse event after successful gene therapy for X-linked severe combined immunodeficiency. N Engl J Med 348:255-256. CrossRef Medline 
Harris NG, Mironova YA, Hovda DA, Sutton RL (2010) Chondroitinase $\mathrm{ABC}$ enhances pericontusion axonal sprouting but does not confer robust improvements in behavioral recovery. J Neurotrauma 27:1971-1982. CrossRef Medline

Hellal F, Hurtado A, Ruschel J, Flynn KC, Laskowski CJ, Umlauf M, Kapitein LC, Strikis D, Lemmon V, Bixby J, Hoogenraad CC, Bradke F (2011) Microtubule stabilization reduces scarring and causes axon regeneration after spinal cord injury. Science 331:928-931. CrossRef Medline

Houle JD, Tom VJ, Mayes D, Wagoner G, Phillips N, Silver J (2006) Combining an autologous peripheral nervous system "bridge" and matrix modification by chondroitinase allows robust, functional regeneration beyond a hemisection lesion of the adult rat spinal cord. J Neurosci 26: 7405-7415. CrossRef Medline

Hunanyan AS, García-Alías G, Alessi V, Levine JM, Fawcett JW, Mendell LM, Arvanian VL (2010) Role of chondroitin sulfate proteoglycans in axonal conduction in Mammalian spinal cord. J Neurosci 30:7761-7769. CrossRef Medline

Iaci JF, Vecchione AM, Zimber MP, Caggiano AO (2007) Chondroitin sulfate proteoglycans in spinal cord contusion injury and the effects of chondroitinase treatment. J Neurotrauma 24:1743-1759. CrossRef Medline

Iseda T, Okuda T, Kane-Goldsmith N, Mathew M, Ahmed S, Chang YW, Young W, Grumet M (2008) Single, high-dose intraspinal injection of chondroitinase reduces glycosaminoglycans in injured spinal cord and promotes corticospinal axonal regrowth after hemisection but not contusion. J Neurotrauma 25:334-349. CrossRef Medline

Jakeman LB, Hoschouer EL, Basso DM (2011) Injured mice at the gym: review, results and considerations for combining chondroitinase and locomotor exercise to enhance recovery after spinal cord injury. Brain Res Bull 84:317-326. CrossRef Medline

James ND, Bartus K, Grist J, Bennet DL, McMahon SB, Bradbury EJ (2011) Conduction failure following spinal cord injury: functional and anatomical changes from acute to chronic stages. J Neurosci 31:18543-18555. CrossRef Medline

Jarraya B, Boulet S, Ralph GS, Jan C, Bonvento G, Azzouz M, Miskin JE, Shin M, Delzescaux T, Drouot X, Hérard AS, Day DM, Brouillet E, Kingsman SM, Hantraye P, Mitrophanous KA, Mazarakis ND, Palfi S (2009) Dopamine gene therapy for Parkinson's disease in a nonhuman primate without associated dyskinesia. Sci Transl Med 1:2ra4. CrossRef Medline

Jefferson SC, Tester NJ, Howland DR (2011) Chondroitinase ABC promotes recovery of adaptive limb movements and enhances axonal growth caudal to a spinal hemisection. J Neurosci 31:5710-5720. CrossRef Medline

Jin Y, Ketschek A, Jiang Z, Smith G, Fischer I (2011) Chondroitinase activity can be transduced by a lentiviral vector in vitro and in vivo. J Neurosci Methods 199:208-213. CrossRef Medline

Jones LL, Sajed D, Tuszynski MH (2003) Axonal regeneration through regions of chondroitin sulfate proteoglycan deposition after spinal cord injury: a balance of permissiveness and inhibition. J Neurosci 23:92769288. Medline

Karimi-Abdolrezaee S, Eftekharpour E, Wang J, Schut D, Fehlings MG (2010) Synergistic effects of transplanted adult neural stem/progenitor cells, chondroitinase, and growth factors promote functional repair and plasticity of the chronically injured spinal cord. J Neurosci 30:1657-1676. CrossRef Medline

Kigerl KA, Gensel JC, Ankeny DP, Alexander JK, Donnelly DJ, Popovich PG (2009) Identification of two distinct macrophage subsets with divergent effects causing either neurotoxicity or regeneration in the injured mouse spinal cord. J Neurosci 29:13435-13444. CrossRef Medline

Kim S, Takahashi H, Lin WW, Descargues P, Grivennikov S, Kim Y, Luo JL, Karin M (2009) Carcinoma-produced factors activate myeloid cells through TLR2 to stimulate metastasis. Nature 457:102-106. CrossRef Medline

Kwok JC, Warren P, Fawcett JW (2012) Chondroitin sulfate: a key molecule in the brain matrix. Int J Biochem Cell Biol 44:582-586. CrossRef Medline

Lee H, McKeon RJ, Bellamkonda RV (2010) Sustained delivery of thermostabilized chABC enhances axonal sprouting and functional recovery after spinal cord injury. Proc Natl Acad Sci U S A 107:3340-3345. CrossRef Medline

Lee YS, Lin CY, Jiang HH, Depaul M, Lin VW, Silver J (2013) Nerve regen- eration restores supraspinal control of bladder function after complete spinal cord injury. J Neurosci 33:10591-10606. CrossRef Medline

Li S, Kim JE, Budel S, Hampton TG, Strittmatter SM (2005) Transgenic inhibition of Nogo-66 receptor function allows axonal sprouting and improved locomotion after spinal injury. Mol Cell Neurosci 29:26-39. CrossRef Medline

Mantovani A, Sozzani S, Locati M, Allavena P, Sica A (2002) Macrophage polarization: tumor-associated macrophages as a paradigm for polarized M2 mononuclear phagocytes. Trends Immunol 23:549-555. CrossRef Medline

Martinez FO, Gordon S, Locati M, Mantovani A (2006) Transcriptional profiling of the human monocyte-to-macrophage differentiation and polarization: new molecules and patterns of gene expression. J Immunol 177:7303-7311. Medline

Massey JM, Hubscher CH, Wagoner MR, Decker JA, Amps J, Silver J, Onifer SM (2006) Chondroitinase ABC digestion of the perineuronal net promotes functional collateral sprouting in the cuneate nucleus after cervical spinal cord injury. J Neurosci 26:4406-4414. CrossRef Medline

McKillop WM, Dragan M, Schedl A, Brown A (2013) Conditional Sox9 ablation reduces chondroitin sulfate proteoglycan levels and improves motor function following spinal cord injury. Glia 61:164-177. CrossRef Medline

Miron VE, Boyd A, Zhao JW, Yuen TJ, Ruckh JM, Shadrach JL, van Wijngaarden P, Wagers AJ, Williams A, Franklin RJ, Ffrench-Constant C (2013) M2 microglia and macrophages drive oligodendrocyte differentiation during CNS remyelination. Nat Neurosci 16:1211-1218. CrossRef Medline

Monaco C, Gregan SM, Navin TJ, Foxwell BM, Davies AH, Feldmann M (2009) Toll-like receptor-2 mediates inflammation and matrix degradation in human atherosclerosis. Circulation 120:2462-2469. CrossRef Medline

Morawski M, Brückner G, Jäger C, Seeger G, Arendt T (2010) Neurons associated with aggrecan-based perineuronal nets are protected against tau pathology in subcortical regions in Alzheimer's disease. Neuroscience 169:1347-1363. CrossRef Medline

Muir EM, Fyfe I, Gardiner S, Li L, Warren P, Fawcett JW, Keynes RJ, Rogers JH (2010) Modification of N-glycosylation sites allows secretion of bacterial chondroitinase ABC from mammalian cells. J Biotechnol 145:103110. CrossRef Medline

Palfi S, Gurruchaga JM, Ralph GS, Lepetit H, Lavisse S, Buttery PC, Watts C, Miskin J, Kelleher M, Deeley S, Iwamuro H, Lefaucheur JP, Thiriez C, Fenelon G, Lucas C, Brugières P, Gabriel I, Abhay K, Drouot X, Tani N, et al. (2014) Long-term safety and tolerability of ProSavin, a lentiviral vector-based gene therapy for Parkinson's disease: a dose escalation, open-label, phase 1/2 trial. Lancet pii:S0140-6736(13)61939-X. CrossRef Medline

Pizzorusso T, Medini P, Berardi N, Chierzi S, Fawcett JW, Maffei L (2002) Reactivation of ocular dominance plasticity in the adult visual cortex. Science 298:1248-1251. CrossRef Medline

Rolls A, Cahalon L, Bakalash S, Avidan H, Lider O, Schwartz M (2006) A sulfated disaccharide derived from chondroitin sulfate proteoglycan protects against inflammation-associated neurodegeneration. FASEB J 20: 547-549. Medline

Saruhashi Y, Young W, Perkins R (1996) The recovery of 5-HT immunoreactivity in lumbosacral spinal cord and locomotor function after thoracic hemisection. Exp Neurol 139:203-213. CrossRef Medline

Schwab ME, Bartholdi D (1996) Degeneration and regeneration of axons in the lesioned spinal cord. Physiol Rev 76:319-370. Medline

Shechter R, Miller O, Yovel G, Rosenzweig N, London A, Ruckh J, Kim KW, Klein E, Kalchenko V, Bendel P, Lira SA, Jung S, Schwartz M (2013) Recruitment of beneficial $\mathrm{m} 2$ macrophages to injured spinal cord is orchestrated by remote brain choroid plexus. Immunity 38:555-569. CrossRef Medline

Sica A, Mantovani A (2012) Macrophage plasticity and polarization: in vivo veritas. J Clin Invest 122:787-795. CrossRef Medline

Siebert JR, Stelzner DJ, Osterhout DJ (2011) Chondroitinase treatment following spinal contusion injury increases migration of oligodendrocyte progenitor cells. Exp Neurol 231:19-29. CrossRef Medline

Silver DJ, Siebzehnrubl FA, Schildts MJ, Yachnis AT, Smith GM, Smith AA, Scheffler B, Reynolds BA, Silver J, Steindler DA (2013) Chondroitin sul- 
fate proteoglycans potently inhibit invasion and serve as a central organizer of the brain tumor microenvironment. J Neurosci 33:15603-15617. CrossRef Medline

Silver J, Miller JH (2004) Regeneration beyond the glial scar. Nat Rev Neurosci 5:146-156. CrossRef Medline

Sooksawate T, Isa K, Matsui R, Kato S, Kinoshita M, Kobayashi K, Watanabe D, Kobayashi K, Isa T (2013) Viral vector-mediated selective and reversible blockade of the pathway for visual orienting in mice. Front Neural Circuits 7:162. Medline

Starkey ML, Bartus K, Barritt AW, Bradbury EJ (2012) Chondroitinase ABC promotes compensatory sprouting of the intact corticospinal tract and recovery of forelimb function following unilateral pyramidotomy in adult mice. Eur J Neurosci 36:3665-3678. CrossRef Medline

Tauchi R, Imagama S, Natori T, Ohgomori T, Muramoto A, Shinjo R, Matsuyama Y, Ishiguro N, Kadomatsu K (2012) The endogenous proteoglycan- degrading enzyme ADAMTS-4 promotes functional recovery after spinal cord injury. J Neuroinflammation 9:53. CrossRef Medline

Tom VJ, Sandrow-Feinberg HR, Miller K, Santi L, Connors T, Lemay MA, Houlé JD (2009a) Combining peripheral nerve grafts and chondroitinase promotes functional axonal regeneration in the chronically injured spinal cord. J Neurosci 29:14881-14890. CrossRef Medline

Tom VJ, Kadakia R, Santi L, Houlé JD (2009b) Administration of chondroitinase $\mathrm{ABC}$ rostral or caudal to a spinal cord injury site promotes anatomical but not functional plasticity. J Neurotrauma 26:2323-2333. CrossRef Medline

Zhao RR, Muir EM, Alves JN, Rickman H, Allan AY, Kwok JC, Roet KC, Verhaagen J, Schneider BL, Bensadoun JC, Ahmed SG, Yañez-Muñoz RJ, Keynes RJ, Fawcett JW, Rogers JH (2011) Lentiviral vectors express chondroitinase $\mathrm{ABC}$ in cortical projections and promote sprouting of injured corticospinal axons. J Neurosci Methods 201:228-238. CrossRef Medline 